\title{
OPEN Improving motor neuron-like cell differentiation of hEnSCs by the combination of epothilone B loaded PCL microspheres in optimized 3D collagen hydrogel
}

Narges Mahmoodi ${ }^{1}$, Jafar Ai $^{2}$, Zahra Hassannejad ${ }^{3}$, Somayeh Ebrahimi-Barough ${ }^{2}$, Elham Hasanzadeh ${ }^{4}$, Houra Nekounam ${ }^{5}$, Alexander R. Vaccaro ${ }^{6}$ \& Vafa Rahimi-Movaghar ${ }^{1 凶}$

Spinal cord regeneration is limited due to various obstacles and complex pathophysiological events after injury. Combination therapy is one approach that recently garnered attention for spinal cord injury ( $\mathrm{SCl}$ ) recovery. A composite of three-dimensional (3D) collagen hydrogel containing epothilone $B(E p o B)$-loaded polycaprolactone (PCL) microspheres $(2.5 \mathrm{ng} / \mathrm{mg}, 10 \mathrm{ng} / \mathrm{mg}$, and $40 \mathrm{ng} / \mathrm{mg}$ EpoB/ $P C L$ ) were fabricated and optimized to improve motor neuron (MN) differentiation efficacy of human endometrial stem cells (hEnSCs). The microspheres were characterized using liquid chromatographymass/mass spectrometry (LC-mas/mas) to assess the drug release and scanning electron microscope (SEM) for morphological assessment. hEnSCs were isolated, then characterized by flow cytometry, and seeded on the optimized 3D composite. Based on cell morphology and proliferation, crosslinked collagen hydrogels with and without $2.5 \mathrm{ng} / \mathrm{mg}$ EpoB loaded PCL microspheres were selected as the optimized formulations to compare the effect of EpoB release on $\mathrm{MN}$ differentiation. After differentiation, the expression of MN markers was estimated by real-time PCR and immunofluorescence (IF). The collagen hydrogel containing the EpoB group had the highest HB9 and ISL-1 expression and the longest neurite elongation. Providing a 3D permissive environment with EpoB, significantly improves MN-like cell differentiation and maturation of hEnSCs and is a promising approach to replace lost neurons after $\mathrm{SCl}$.

Spinal cord injury (SCI) is a very common traumatic event and is mainly caused by falls and motor vehicle accidents (MVAs) ${ }^{1,2}$. Extensive neuron loss and axon degeneration are common cellular findings at the lesion site following SCI, leading to severe disability in patients due to limited neuronal regeneration and recovery ${ }^{3-5}$.

Currently, no therapy is available for complete functional recovery after $\mathrm{SCI}^{6,7}$, however, advances in medical care can increase life expectancy in patients with SCI and reduce their families' financial burden ${ }^{8,9}$. As a growing research area, using various stem cells has been garnered great attention for nerve tissue regeneration through cell differentiation for lost cell replacement, anti-inflammatory effects, and neurotrophic factor secretion ${ }^{4,10}$.

However, stem cell therapy utility is usually limited given low cell survival and uncontrollable cell differentiation at the site of injury ${ }^{4}$. SCI also leads to complex, destructive biological processes that may continue up to one year after injury ${ }^{11}$. Thus, to reach the full potential of stem cells, a synergistic effect through combination therapy is necessary ${ }^{12}$.

${ }^{1}$ Sina Trauma and Surgery Research Center, Tehran University of Medical Sciences, Tehran, Iran. ${ }^{2}$ Department of Tissue Engineering and Applied Cell Sciences, School of Advanced Technologies in Medicine, Tehran University of Medical Sciences, Tehran, Iran. ${ }^{3}$ Pediatric Urology and Regenerative Medicine Research Center, Tissue, Cell and Gene Research Institute, Tehran University of Medical Sciences, Tehran, Iran. ${ }^{4}$ Immunogenetics Research Center, Department of Tissue Engineering and Applied Cell Sciences, School of Advanced Technologies in Medicine, Mazandaran University of Medical Sciences, Sari, Iran. ${ }^{5}$ Department of Medical Nanotechnology, School of Advanced Technologies in Medicine, Tehran University of Medical Sciences, Tehran, Iran. ${ }^{6}$ Department of Orthopedic Surgery, Rothman Institute, Thomas Jefferson University, Philadelphia, PA, USA. ${ }^{\square}$ email: v_rahimi@ tums.ac.ir 
One of the most promising stem cells for SCI therapy is a group of adult multipotent mesenchymal stem cells (MSCs), which can be induced to different cell types ${ }^{13-15}$. Human endometrial stem cells (hEnSCs) as a MSCs have considered attention for cell therapy and tissue engineering ${ }^{16-20}$. Interestingly, in a recent study, a comparison between hEnSCs and human bone marrow stem cells (hBM-MSCs) showed a better motor neuron (MN) differentiation potential for $\mathrm{hEnSCs}^{21}$. Improvement in differentiating stem cells into specialized neurons is one solution for replacing damaged or lost cells, thereby leading to potential functional recovery ${ }^{22}$.

Motor neurons are a type of nerve cells that end at myocytes and transfer nerve impulses to control voluntary muscle movements. After SCI, there is a substantial loss of motor neurons and interneurons in the spinal cord tissue $^{23}$, while endogenous regeneration of neurons and revival of motor function is limited ${ }^{24}$. A spectrum of illnesses such as spinal muscular atrophy (SMA) and amyotrophic lateral sclerosis (ALS) can also lead to motor neuron degeneration ${ }^{25}$. To cure these illnesses, researchers are trying to develop methods to produce MN-like cells from stem cells ${ }^{26}$. MN-derived cells can also be utilized for MN-modelling and drug-screening assays ${ }^{27,28}$.

Microtubules (MTs) are a type of cytoskeletons that, as a structural component, are essential for cellular polarization, neuronal morphology, axonal regeneration, motility, protein secretion, and intracellular movement ${ }^{29,30}$. MTs disruption and disorganization are characteristics of damaged nerve cells after $\mathrm{SCI}^{31,32}$. Likewise, MTs disorganization has been noticed as a primary etiology of neurodegenerative diseases such as Alzheimer's and Parkinson's diseases ${ }^{33,34}$, and, recently, microtubule-stabilizing agents (MSAs) have been considered in the treatment strategy of these disorders ${ }^{35}$.

Epothilone B (EpoB), also known as patupilone, is a macrolide derived from myxobacteria Sorangium cellulosum and an MSA that can cross the blood-brain barrier (BBB). A recent study showed that EpoB can induce axon regeneration and elongation in damaged nerve cells and decrease scar formation after SCI in rodents ${ }^{36-38}$. These studies, however, used systemic administration of drugs, and the possible side effects and short half-life limit us from reaching maximal efficacy. Moreover, various injections require invasive medical intervention. A biocompatible and biodegradable delivery system can offer sustained release of therapeutic agents and thus increase their effectiveness without using excessive invasive surgical techniques ${ }^{24}$. For the delivery of drugs, they can be encapsulated into biomaterial-based microspheres for sustained release, which provides in situ sustained release ${ }^{39}$.

In the field of tissue engineering, utilizing naturally derived hydrogels have gained momentum for localized drug delivery application for presenting easily mimicking and integrating with native tissues, for similar characteristics to soft tissues, and their excellent recognition by different cell types ${ }^{40-42}$.

Among various natural-based hydrogels, collagen is the major protein of the extracellular matrix (ECM) in many mammalian tissues ${ }^{43}$. Collagen is distinguished being a highly biocompatible cellular growth supporter and is noncytotoxic ${ }^{44}$. Though collagen has been extensively used in the clinic and tissue engineering for various applications ${ }^{45}$, its high degradation degree, mechanical instability, and thermosensitivity have led researchers to add other polymers or cross-linkers to achieve more desirable features ${ }^{40,46}$. Therefore, in this study, we chose a cross-linking approach to improve hydrogel stability while preserving the utility of collagen hydrogel as an appropriate three-dimensional (3D) structure for enhancing cell proliferation and differentiation. Many different kinds of cross-linked hydrogels have been used as 3D scaffolds and drug delivery systems for soft tissue engineering, including corneal, cartilage, skin, tendon, and peripheral and central nervous tissues ${ }^{47-49}$.

Proanthocyanidin (PA) is a natural polyphenolic oligomeric flavonoid found in flowers, vegetables, fruits, seeds, nuts, and barks ${ }^{50,51}$. PA is a promising cross-linker with a variety of biological activities, including antiinflammatory, anti-tumor, antioxidant, anti-bacterial, anti-calcification. PA provides biocompatible crosslinked hydrogels and has non-toxicity properties, unlike common cross-linkers such as formaldehyde and glutaraldehyde $\mathrm{e}^{52-55}$.

Evidence shows that combination strategies achieve greater results than using each component separately by addressing various aspects of SCI pathophysiology ${ }^{12}$. Accordingly, in this study, we aimed to enhance the differentiation potential of hEnSCs into MN-like cells and axonal elongation using the signaling molecules sonic hedgehog (SHH) and retinoic acid (RA), and also by providing a hydrogel-based 3D microenvironment capable of controlling the release of EpoB using PCL microspheres.

\section{Materials and methods}

Isolation and culture of human endometrial stem cell (hEnSC). hEnSCs were isolated according to a previous study ${ }^{56}$. The collection of discarded endometrium biopsies from patients was achieved via the informed consent from the patients/legal guardian. All methods were performed in accordance with the relevant guidelines and regulations of Tehran University of Medical Sciences and approved by the university's ethical committee (code: IR.TUMS.REC.1394.1137). Briefly, biopsies of endometrium were washed with phosphatebuffered saline (PBS; Sigma, P4417) containing 2-3\% amphotericin B and penicillin/streptomycin, were cut into small pieces and digested with collagenase type I $(1 \mathrm{mg} / \mathrm{mL}$, Sigma-Aldrich) in Dulbecco's Modified Eagle Medium/Nutrient Mixture F-12 (DMEM-F12; Invitrogen) for $2 \mathrm{~h}$ at $37^{\circ} \mathrm{C}$. The enzyme was then neutralized by adding a complete medium composed of DMEM-F12 with 10\% fetal bovine serum (FBS; Gibco, 10270-106). Subsequently, the samples were passed through $70 \mu \mathrm{m}$ and $40 \mu \mathrm{m}$ filters and were centrifuged at $1200 \mathrm{rpm}$ for $5 \mathrm{~min}$. After the supernatant was removed, the pellet of cells was resuspended in a complete medium containing $10 \%$ FBS and $1 \%$ penicillin/streptomycin. The cell suspension was transferred to 6-well cell culture plates and incubated in a humidified chamber at $37^{\circ} \mathrm{C}$ with $5 \% \mathrm{CO}_{2}$. The medium was exchanged every 3 days. Three or four passages of hEnSCs were used for all of our experiments.

Flow cytometry. To confirm the identity of the isolated cells, passage three cells were used for flow cytometry BD FACSCalibur (BD Biosciences, USA). The evaluated markers were as follows: endometrial stem cell 


\begin{tabular}{|l|l|l|l|l|}
\hline & Cell surface marker & Percentage (\%) & Antibody & Catalog number \\
\hline Endometrial stem cell marker & CD146 & 89.1 & PE-conjugated anti-CD146 & BD Biosciences, 561013 \\
\hline \multirow{3}{*}{ Mesenchymal stem cell marker } & CD105 & 98.4 & PerCP-conjugated anti-CD105 & BioLegend, 323216 \\
\cline { 2 - 5 } & CD90 & 98.4 & FITC-conjugated anti-CD90 & Exbio, 1F-652-100T \\
\cline { 2 - 5 } & CD44 & 98.5 & FITC- conjugated anti-CD44 & Immunostep, 44F2-100T \\
\hline \multirow{2}{*}{ Hemopoietic stem cell marker } & CD45 & 0.3 & FITC-conjugated anti-CD45 & BD Biosciences, 560976 \\
\cline { 2 - 5 } & CD34 & 0.8 & PE-conjugated anti-CD34 & Exbio, 1P-664-T025 \\
\hline Endothelial marker & CD31 & 0.3 & PE-conjugated anti-CD31 & Immunostep, 31PE-100T \\
\hline
\end{tabular}

Table 1. Markers for hEnSCs identification. PE phycoerythrin, PerCP peridinin chlorophyll protein, FITC fluorescein isothiocyanate.

marker (CD146), mesenchymal stem cell markers (CD44, CD90, and CD105), hematopoietic stem cell markers (CD34 and CD45), and endothelial stem cell markers (CD31).

The cells were washed three times with Hank's Balanced Salt Solution (HBSS) and 2\% bovine serum albumin (BSA; Sigma, A7030) and then were incubated with a specific antibody (Table 1) at concentrations recommended by the respective manufacturers (for $1 \mathrm{~h}$ ). Data were evaluated by FlowJo Version 7 software.

Green fluorescent protein (GFP) labeled hEnSCs. Based on previous studies, lentivirus (second-generation) was used for GFP gene transduction of hEnSCs and HEK293-T cells ${ }^{57}$. We also labeled HEK293-T as the standard cell line with high efficiency for GFP labeling. The pCDHCop GFP-Pru plasmid was used for labeling, which contained EF-1a promotor to upregulate the expression of GFP transgene. For transient transfection of HEK293-T, the vector associated with psPAX2 as a packaging plasmid and PMD2.G as an envelope plasmid were used via the calcium phosphate precipitation method. Then, the viral particles were harvested from the supernatant for 3 days, then stored at $-80{ }^{\circ} \mathrm{C}$. HEK293-T (30\% confluency) and hEnSCs (50\% confluency) were then transduced by adding $5 \mu \mathrm{g} / \mathrm{mL}$ polybrene and lentiviral particles. Labeled cells were selected using $10 \mu \mathrm{g} / \mathrm{mL}$ puromycin, which was added to DMEM-F12. GFP expression was observed in hEnSCs via fluorescent microscopy after 3 days.

Microsphere fabrication and sterilization. The oil in water $(\mathrm{o} / \mathrm{w})$ single emulsion method was used to synthesize the EpoB-loaded PCL microspheres. First, $250 \mathrm{mg}$ of polycaprolactone (PCL; Sigma, 363170) was dissolved in $2 \mathrm{~mL}$ of dichloromethane (DCM; Sigma, 32222) using a magnet stirrer (Heidolph, Hei-Tec) for $25 \mathrm{~min}$ at $35^{\circ} \mathrm{C}$. Three groups of EpoB-loaded PCL microspheres were fabricated by adding $0.625 \mu \mathrm{g}, 2.5 \mu \mathrm{g}$, and $10 \mu \mathrm{g}$ of EpoB (Abcam, 152044-54-7) to the PCL solution for an EpoB loading of $2.5 \mathrm{ng} / \mathrm{mg}, 10 \mathrm{ng} / \mathrm{mg}$, and $40 \mathrm{ng} / \mathrm{mg}$ (EpoB/PCL), respectively. Unloaded microspheres were synthesized through the elimination of EpoB from the formulation. $2 \mathrm{~mL}$ of pure ethanol (Merck, 111727) was added to the solution while stirring, and $2 \mathrm{~mL}$ of $2 \%$ (w/v) polyvinyl alcohol (PVA) (Sigma, 363170) solution was slowly added drop by drop without disrupting the boundary layer. Then, the solution was mixed and emulsified for $12 \mathrm{~s}$ using a vortexer (Heidolph) and instantly added to a $100 \mathrm{~mL}$ beaker containing $50 \mathrm{~mL}$ of $0.3 \%(\mathrm{w} / \mathrm{v})$ PVA solution at $35^{\circ} \mathrm{C}$. To evaporate the organic solvent, the solution was stirred with a $3 \mathrm{~cm} \times 0.5 \mathrm{~cm}$ round magnetic stirring bar at 500 revolutions per minute $(\mathrm{rpm})$ for $4 \mathrm{~h}$ in a $100 \mathrm{~mL}$ beaker. Since EpoB is light sensitive, the entire fabrication process was performed in a dark room. It is worth noting, due to the importance of mentioning parameters such as magnetic bar's length, diameter, and the size of cylindrical container for having a reproducible particle synthesis method, these specifications were mentioned above ${ }^{58}$.

The synthesized microspheres were collected through centrifugation at $4000 \mathrm{rpm}$ (Eppendorf, 5810R) for $10 \mathrm{~min}$ and were washed four times with distilled water and centrifugation at $4000 \mathrm{rpm}$ for $5 \mathrm{~min}$ each time to remove residual PVA. Then, the microspheres were frozen at $-80^{\circ} \mathrm{C}$, lyophilized for $24-48 \mathrm{~h}$, and were stored at $-20^{\circ} \mathrm{C}$. For cell culture experiments, microspheres were sterilized by air-plasma for $30 \mathrm{~s}$ on low power (Harrick, PDC-32G).

Microsphere characterization. Scanning electron microscopy (SEM). To evaluate the size and morphology of microspheres, a ZEISS DSM 960A Oberkochen (Germany) scanning electron microscope (SEM) was used. Microspheres were sputter-coated with gold ( $20 \mathrm{kV}$ for $4 \mathrm{~min}$ ), and after imaging, their diameters were quantified using ImageJ software. The distribution of microsphere diameters was plotted as a histogram. Each sample was displayed from smallest to largest diameter.

Determination of encapsulation efficiency (EE). After synthesizing $2.5 \mathrm{ng} / \mathrm{mg}, 10 \mathrm{ng} / \mathrm{mg}$, and $40 \mathrm{ng} / \mathrm{mg}$ (w/w, EpoB/PCL) EpoB microspheres, the suspension of each group was centrifuged at $4000 \mathrm{rpm}$ for $10 \mathrm{~min}$ at room temperature to separate the microparticles and supernatant. The amount of EpoB in the supernatant was evaluated as the extent of unencapsulated EpoB using liquid chromatography-mass/mass spectrometry (LC-Mas/ Mas; HPLC Alliance 269S Waters, Quattro Micro API micromass micromass) with a C18 column $(4.8 \times 150 \mathrm{~mm}$, $5 \mu \mathrm{m}$, Agilent Zorbax XDB). The standard solutions of EpoB and each microsphere sample were loaded to LC-MS/MS and first eluted with methanol: water (40:60) for $5 \mathrm{~min}$ at the speed of $0.5 \mathrm{~mL} / \mathrm{min}$ and then 
methanol:water (95:5). The retention time of EpoB was $9 \mathrm{~min}$. The samples were quantified based on the standard curve of EpoB (all samples were run in triplicate).

The encapsulation efficiency (EE) of EpoB in the PCL microparticle was determined as the following formula:

$$
\mathrm{EE} \%=\frac{\text { Total Epo B added }(n g)-\text { Unbound Epo B }(n g)}{\text { Total EpoB used }(n g)} \times 100 \%
$$

EpoB release measurement. $10 \mathrm{mg}$ of $2.5 \mathrm{ng} / \mathrm{mg}, 10 \mathrm{ng} / \mathrm{mg}$, and $40 \mathrm{ng} / \mathrm{mg}$ (w/w, EpoB/PCL) EpoB-loaded microspheres were suspended in $1.5 \mathrm{~mL}$ of PBS in a Costar Spin- $\mathrm{X}^{\circ}$ centrifuge tube filter $(0.22 \mu \mathrm{m}$ pore CA membrane; Corning, 8160). The microspheres were placed in the above chamber containing the filter, filled with $0.5 \mathrm{~mL}$ PBS, and the tube filled with $1 \mathrm{~mL}$ PBS. These tubes were used to prevent microspheres from being mistakenly collected at the time of sampling. The Costar ${ }^{\circ}$ Spin- $\mathrm{X}^{\circ}$ centrifuge tubes were then placed on a shaker (Lab Tech, LSI-3016R) at $100 \mathrm{rpm}$ and incubated at $37^{\circ} \mathrm{C}$. For the in vitro study, to simulate the conditions of exchanging the culture medium, in the release test, the PBS was exchanged every 2 days. Three samples were considered for each time point (7-time points: 1 and $18 \mathrm{~h}$ and 1, 3, 6, 14, and 21 days). The PBS of each sample was collected entirely at each time point. First, the PBS of the tubes was collected (not the above chamber that contained the filter), then each chamber was centrifuged with its tube at $4000 \mathrm{rpm}$ for $5 \mathrm{~min}$ until the PBS in the chamber inter the tube and could be collected. The PBS was then stored at $-80^{\circ} \mathrm{C}$ and protected from light until all the samples were collected for further analysis.

The amount of EpoB was determined by using LC-Mas/Mas. In addition, to better identify the drug amount, the samples were first concentrated six times. For this purpose, each $1.5 \mathrm{~mL}$ samples were freeze-dried for $24-48 \mathrm{~h}$ and then dissolved in $200 \mu \mathrm{L}$ deionized water and $50 \mu \mathrm{L}$ methanol. For cell culture application, the candidate microspheres were then sterilized by air plasma (Harrick, PDC-32G) on low power for $30 \mathrm{~s}$.

Determining the effect of microspheres on cell viability and proliferation. According to experimental release results, the microsphere containing $2.5 \mathrm{ng} / \mathrm{mg}$ (EpoB/PCL) was selected as the candidate microsphere for this study, referred to as Mic-2.5-EpoB in this text. To determine the biocompatible concentration of microparticles for hEnSCs culture, first, different concentrations of unloaded PCL microspheres $(5,10,15$, and $40 \mathrm{mg} / \mathrm{mL}$ ) were used by indirect MTT assay for 24,48 , and $72 \mathrm{~h}$. After evaluating their results, a second indirect MTT assay was performed for Mic-2.5-EpoB for 24,48 , and $72 \mathrm{~h}$ to assess the effect of the loaded microsphere on viability and proliferation of hEnScs. For both MTT assays, $2 \times 10^{5} \mathrm{hEnSCs}$ were seeded in each 24 -well cell culture plate containing $500 \mu \mathrm{L}$ of complete medium and incubated at $37^{\circ} \mathrm{C}, 5 \% \mathrm{CO}_{2}$ for $24 \mathrm{~h}$. Then, the cell culture was replaced with extract solutions of the microspheres and incubated at $37^{\circ} \mathrm{C}, 5 \% \mathrm{CO}_{2}$ for 24,48 , and $72 \mathrm{~h}$. The microsphere extract solutions of the $(5,10,15$, and $40 \mathrm{mg} / \mathrm{mL}$ unloaded PCL microspheres and Mic2.5 -EpoB) in complete medium (DMEM-F12 + 10\% FBS) were collected every $24 \mathrm{~h}$ (each group was performed in triplicate). For each time point, the medium was removed and replaced with $5 \mathrm{mg} / \mathrm{mL}$ tetrazolium (Sigma) in PBS (MTT solution) and incubated for $3 \mathrm{~h}$ at $37^{\circ} \mathrm{C}, 5 \% \mathrm{CO}_{2}$. The optical density (OD) of formazan dye dissolved in dimethyl sulfoxide solution (DMSO) was obtained using an ELISA microplate reader (Gen5, Power Wave XS2, BioTek, USA) at $590 \mathrm{~nm}$. The following formula calculated the cell viability percent of hEnSCs:

$$
\% \text { Cell Viability }=\frac{\text { OD treated well }}{\text { OD control well }} \times 100
$$

The MTT test was also used to determine the permissible particle limit in the cell culture for hEnSCs.

Fabrication of collagen hydrogels. Collagen type I was extracted from rat tails following a previously developed method ${ }^{59}$. Collagen was sterilized through dialysis with $1 \%$ chloroform (Merck) using dialysis bags with a molecular cut of 6-8 $\mathrm{kDa}$ (SpectraPor, 132660) for $1 \mathrm{~h}$ at $4{ }^{\circ} \mathrm{C}$.

Collagen hydrogels were fabricated using a ratio of $8: 1: 1$ of sterile collagen solution: $10 \times$ DMEM/F12:HSS buffer. The HSS buffer was prepared by dissolving $4.77 \mathrm{~g}$ HEPES and $2.2 \mathrm{~g}$ sodium bicarbonate in $100 \mathrm{~mL}$ of $0.5 \mathrm{M}$ sodium hydroxide. For gelation, $500 \mu \mathrm{L}$ of the prepared mixture was poured into 24 -well cell culture plates and incubated at $37^{\circ} \mathrm{C}$ for $1 \mathrm{~h}$. Two final concentrations of collagen were used to fabricate the hydrogels: $2 \mathrm{mg} /$ $\mathrm{mL}$ and $4 \mathrm{mg} / \mathrm{mL}$.

To improve stability of the hydrogel, collagen hydrogels were also cross-linked using different concentrations of proanthocyanidin (Grape Seed, Proanthocyanidins, Shari, Iran) in PBS, including 0.25\% PA, 0.5\% PA, and also $0.5 \% \mathrm{PA}$ with $0.05 \mathrm{M} \mathrm{Ca}(\mathrm{OH})_{2}\left(\mathrm{PA}-\mathrm{Ca}(\mathrm{OH})_{2}\right)$. In the last formulation, we used $\mathrm{Ca}(\mathrm{OH})_{2}$ based on evidence indicating that $\mathrm{Ca}(\mathrm{OH})_{2}$ facilitates the penetration of $\mathrm{PA}$ and collagen cross-linking ${ }^{52}$. After one-hour incubation of collagen solutions $(2 \mathrm{mg} / \mathrm{mL}$ and $4 \mathrm{mg} / \mathrm{mL})$ at $37^{\circ} \mathrm{C}, 100 \mu \mathrm{L}$ of PA solution was added, and the cell culture plates were further incubated for $48 \mathrm{~h}$ at room temperature in a sterile condition. Then, the hydrogels were washed with PBS three times to remove the excess crosslinkers. The specifications of hydrogel preparation are summarized by code in Table 2 .

Fabrication of collagen hydrogel containing EpoB-loaded microspheres. To mix EpoB microspheres with collagen hydrogel for 3D culture application, candidate microspheres were coated with a dilute sterilized collagen solution $(0.5 \mathrm{mg} / \mathrm{mL})$ overnight at $4{ }^{\circ} \mathrm{C}$. Before coating, the collagen solution was neutralized using a $1 \mathrm{~N}$ solution of filter-sterilized $\mathrm{NaOH}$ in water (syringe-filter $0.22-\mu \mathrm{m}$ membrane), bringing the $\mathrm{pH}$ to around 7.4 . 


\begin{tabular}{|l|l|}
\hline Hydrogel code & Desorption \\
\hline Collagen & Collagen hydrogel \\
\hline 2-Col/PA-CH & Cross-linked $2 \mathrm{mg} /$ collagen hydrogel with 0.5\% proanthocyanidin and calcium hydroxide \\
\hline 4-Col/PA-CH & Cross-linked $4 \mathrm{mg} /$ collagen hydrogel with $0.5 \%$ proanthocyanidin and calcium hydroxide \\
\hline 2-Col/PA-CH/Mic EpoB & $\begin{array}{l}\text { Cross-linked } 2 \mathrm{mg} / \mathrm{mL} \text { collagen hydrogel with 0.5\% proanthocyanidin (PA) and calcium hydroxide and } 2.5 \mathrm{ng} / \\
\mathrm{mL} \text { Epo B microspheres }\end{array}$ \\
\hline 4-Col/PA-CH/Mic EpoB & $\begin{array}{l}\text { Cross-linked } 4 \mathrm{mg} / \mathrm{mLcollagen} \mathrm{hydrogel} \mathrm{with} 0.5 \% \text { proanthocyanidin (PA) and calcium hydroxide and 2.5 ng/ } \\
\text { mL Epo B microspheres }\end{array}$ \\
\hline
\end{tabular}

Table 2. The code used for different hydrogels prepared through thermal and chemical cross-linking.

Cell seeding within the collagen hydrogels. In each 24 -well culture plate, $50 \mu \mathrm{L}$ of $1 \times 10^{5} \mathrm{hEnSC}$ in complete medium (DMEM-F12 and 10\% FBS) was slowly added to collagen hydrogels and incubated for $30 \mathrm{~min}$ at $37^{\circ} \mathrm{C}$ for cells attachment. Then, $150 \mu \mathrm{L}$ complete medium was added to each well.

Cell morphology, attachment, and proliferation on the collagen hydrogels. Fluorescent microscopy. To study cell adhesion, morphology, and proliferation in collagen hydrogels, two types of GFP-labeled cells (HEK293-T and hEnSCs) were used. In each 24 -well cell culture plate, $1 \times 10^{5}$ cells were seeded and incubated at $37^{\circ} \mathrm{C}$ with $5 \% \mathrm{CO}_{2}$. To observe the cells, an Olympus (BX51, Japan) immunofluorescence microscope was used.

Scanning electron microscope. An SEM (AIS2300C SEI, Korea) at $20 \mathrm{kV}$ was used for investigating cell attachment of hEnSCs on collagen, 2-Col/PA-CH, and 2-Col/PA-CH/Mic EpoB hydrogel scaffolds, after $48 \mathrm{~h}$ of cell seeding. The SEM was also performed for observing the surface morphology of collagen, 2-Col/PA, 2-Col/ $\mathrm{PA}-\mathrm{CH}$, and 2-Col/PA-CH/Mic EpoB hydrogel scaffolds. The medium of each 24 -well was discarded, and each specimen was washed with PBS and fixed with Karnovsky's fixative solution (consisting of $\%$ paraformaldehyde and $2.5 \%$ glutaraldehyde) at room temperature for $1 \mathrm{~h}$. Subsequently, the prepared samples were washed twice with PBS and then dehydrated with a graded ethanol series of 30,50, 70, 90, 95, and 100\%. Afterward, to examine the specimens via SEM, the samples for cell attachment study were first dried on an aluminum foil at room temperature, and the samples for surface morphology study were freeze-dried for $48 \mathrm{~h}$, then each sample was under vacuum and finally coated with gold sputtering.

Hydrogel biodegradation degree. We assessed the degradation degree of collagen, 2-Col/PA-CH, and 2-Col/PA-CH/Mic EpoB hydrogels based on their weight loss in DMEM-F12 medium at $37^{\circ} \mathrm{C}$. The DMEM-F12 medium was exchanged every 3 days. Hydrogel weight alterations were evaluated over 14 days (all time points were run in triplicate). The degradation degree was calculated using the following equation:

$$
\text { Degradation degree }=\frac{\left(W_{0}-W_{t}\right)}{W_{0}} 100 \%
$$

where, $W_{0}$ and $W_{t}$ indicate the weight of hydrogels before and after immersing in medium, respectively.

Swelling degree. The swelling degree of the hydrogel scaffolds, including collagen, 2-Col/PA-CH, and 2-Col/PA-CH/Mic EpoB were measured for $96 \mathrm{~h}$. The hydrogels were allowed to swell in DMEM-F12 at $37^{\circ} \mathrm{C}$. Each time point was performed in triplicate.

The weight of the wet samples was measured, and the swelling degree was obtained via the following formula:

$$
\text { Swelling degree }=\frac{\left(W_{t}-W_{0}\right)}{W_{0}} \times 100
$$

where, $W_{0}$ and $W_{t}$ are the weight of the primitive hydrogel and the weight of the swollen hydrogel, respectively.

ATR-FTIR spectroscopy. Proanthocyanidin (PA; GrapeSeed, Shari, Iran) blended tablets were first dissolved in water. Then the precipitated additives of the tablet were removed and filtered through a $0.22 \mu \mathrm{m} \mathrm{mem-}$ brane. The samples (PA, Collagen, 2-Col/PA, and 2-Col/PA-CH) were freeze-dried for $48 \mathrm{~h}$ and then analyzed using an ATR accessory (Nicolet Avatar, Thermo Fisher Scientific, Waltham, MA, USA).

Differentiation of hEnSCs into motor neuron-like cells within 3D collagen hydrogels containing EpoB-loaded microspheres. Differentiation of hEnSCs was conducted in a three-step approach ${ }^{26}$ using 24-well cell culture plates with different experimental groups, including collagen hydrogel without Mic EpoB (2-Col/PA-CH), collagen hydrogel with Mic EpoB (2-Col/PA-CH/Mic EpoB), tissue culture plate (TCP; hEnSCs differentiation without Mic EpoB and collagen hydrogel), and control (undifferentiated hEnSCs). $2 \times 10^{5}$ hEnSCs in complete medium (DMEM/F12 and 10\% FBS) at passage three were seeded on different substrates and incubated at $37{ }^{\circ} \mathrm{C}$ and $5 \% \mathrm{CO}_{2}$. After $24 \mathrm{~h}$, in step one, the complete medium was replaced with a preinduction (PrI) medium, and cells were incubated for $24 \mathrm{~h}$. In step two, the PrI medium was exchanged with the induction medium, and cells were incubated for 7 days (the medium was exchanged after 3 days). In step three, 


\begin{tabular}{|c|c|c|c|c|}
\hline Step & Differentiation medium & Ingredients & Catalog number & Duration \\
\hline \multirow{6}{*}{1} & \multirow{6}{*}{ Pre-induction (PrI) medium } & DMEM/F12 (1:1) & Invitrogen, 32500-035 & \multirow{6}{*}{1 days } \\
\hline & & $20 \%$ FBS & Gibco, 10270-106 & \\
\hline & & 2\% B-27 supplement & Gibco, 17504-044 & \\
\hline & & $100 \mu \mathrm{M}$ 2-Mercaptoethanol & Sigma, M3148 & \\
\hline & & $250 \mu \mathrm{M}$ isobutylmethylxanthine (IBME) & Sigma, I5879 & \\
\hline & & $10 \mathrm{ng} / \mathrm{mL}$ fibroblast growth factor 2 (FGF2) & Sigma, SRP4037 & \\
\hline \multirow{4}{*}{2} & \multirow{4}{*}{ Induction medium (exchanged after 3 days) } & DMEM/F12 (1:1) & Invitrogen, 32500-035 & \multirow{4}{*}{7 days } \\
\hline & & $0.2 \%$ B-27 supplement & Gibco 17504-044 & \\
\hline & & $100 \mathrm{ng} / \mathrm{mL}$ sonic hedgehog $(\mathrm{SHH})$ & Sigma, SRP3156 & \\
\hline & & $0.01 \mu \mathrm{M}$ retinoic acid (RA) & Sigma, R2625 & \\
\hline \multirow{4}{*}{3} & \multirow{4}{*}{$\begin{array}{l}\text { Maturation (survival) medium (exchanged } \\
\text { after } 3 \text { days) }\end{array}$} & DMEM/F12 (1:1) & Invitrogen, 32500-035 & \multirow{4}{*}{7 days } \\
\hline & & $0.2 \% \mathrm{~B}-27$ supplement & Gibco 17504-044 & \\
\hline & & $\begin{array}{l}100 \mathrm{ng} / \mathrm{mL} \text { glial cell-derived neurotrophic } \\
\text { factor (GDNF) }\end{array}$ & Sigma, G1777 & \\
\hline & & $\begin{array}{l}200 \mathrm{ng} / \mathrm{mL} \text { brain-derived neurotrophic factor } \\
\text { (BDNF) }\end{array}$ & Sigma, SRP3014 & \\
\hline
\end{tabular}

Table 3. The procedure and reagents used for differentiation of hEnSCs into motor neuron-like cells on 3D collagen hydrogels with or without EpoB-loaded PCL microspheres or cell culture plates.

\begin{tabular}{|c|c|c|}
\hline Antibody/stain & Catalog number & Dilution \\
\hline \multicolumn{3}{|l|}{ Primary antibody } \\
\hline Anti-beta-III-tubulin antibody (Tuj-1) (rabbit monoclonal) & Abcam, ab68193 & $1: 200$ \\
\hline Anti-Islet-1 (mouse monoclonal) & Abcam, ab86472 & $1: 200$ \\
\hline Anti-choline acetyltransferase (CHAT; mouse monoclonal) & Santa Cruz, sc-55557 & $1: 200$ \\
\hline Anti-nestin (NES; mouse monoclonal) & PadzaCo, MN105 & $1: 200$ \\
\hline Anti-Homeobox 9 (HB9; mouse monoclonal) & Santa Cruz, sc-515769 & $1: 50$ \\
\hline \multicolumn{3}{|l|}{ Secondary antibody } \\
\hline Goat anti-rabbit IgG $(\mathrm{H}+\mathrm{L})$ cross-adsorbed secondary antibody, Alexa Fluor 488 & Gibco, A-11008 & $1: 500$ \\
\hline Goat anti-mouse IgG $(\mathrm{H}+\mathrm{L})$ highly cross-adsorbed secondary antibody Alexa Fluor 594 & Gibco, A-11032 & $1: 700$ \\
\hline \multicolumn{3}{|l|}{ Nuclear stain } \\
\hline 4',6-Diamidino-2-phenylindole (DAPI) & Sigma-Aldrich, D8417 & $1: 1000$ \\
\hline
\end{tabular}

Table 4. Primary and secondary antibodies were used for immunofluorescence staining.

the induction medium was replaced with a maturation medium, and incubation was continued for an additional 7 days (the medium was exchanged after 3 days). All procedures and reagents are summarized in Table 3.

Immunofluorescence (IF) staining. All samples were fixed using $4 \%$ paraformaldehyde in PBS for $30 \mathrm{~min}$ at room temperature and then permeabilized using $0.2 \%$ Triton X-100/PBS. The cells were blocked using 5\% BSA/PBS for $45 \mathrm{~min}$ at room temperature and incubated overnight with primary antibodies at $4{ }^{\circ} \mathrm{C}$ (Table 4). Then, each sample was washed three times with PBS/Tween 20 (0.1\%, Sigma). Secondary antibodies were added, and samples were kept in the dark for one hour at room temperature. Cells were again washed with PBS/Tween 20 (0.1\%) three times. Cell nuclei were counterstained with 4',6-diamidino-2-phenylindole (DAPI; Sigma-Aldrich, D8417). For the negative control group, only secondary antibodies were used.

RNA extraction and cDNA synthesis. Total RNA extraction was conducted using RNX Plus ${ }^{\text {Tx }}$ low copy RNA isolation (CinnaGen, Iran, EX6101), chloroform, isopropyl alcohol, and 75\% ethanol. The purity and quantity of each extracted RNA were assessed using a Nanodrop spectrophotometer (Thermo Scientific, USA). cDNA synthesizing was conducted using PrimeScript ${ }^{\mathrm{Tw}} \mathrm{RT}$ Reagent Kit (Takara, RR037A) following the manufacturer's instruction (Thermocycler schedule: $15 \mathrm{~min}$ at $37^{\circ} \mathrm{C}, 5 \mathrm{~s}$ at $85^{\circ} \mathrm{C}$ ).

Real-time RT-PCR for gene expression analysis. All primers were obtained from Qiagen (Germany) (Table 5). RealQ RNA quantitative measurement was evaluated using Plus $2 \times$ Master Mix Green (AMPLIQON, 5000850-1250) on a real-time thermocycler (Rotor-Ge4ne Q, Corbett Life Science, USA) (Table 6). PCR product specificity was evaluated by confirming a single peak in the melting curve analysis. All experimental samples were performed three times in duplicate. RPL13A was selected as a housekeeping gene, and each gene fold- 


\begin{tabular}{|l|l|l|l|l|}
\hline Gene & Assay name & Catalog number (Qiagen) & Genebank accession number & Amplicon length (bp) \\
\hline NES [Human] & $\begin{array}{l}\text { Hs_NES_2_SG QuantiTect } \\
\text { Primer Assay }\end{array}$ & QT01015301 & NM_006617 & 75 \\
\hline ISL1 [Human] & $\begin{array}{l}\text { Hs_ISL1_1_SG QuantiTect } \\
\text { Primer Assay }\end{array}$ & QT00000294 & NM_002202 & 83 \\
\hline NEFH [Human] & $\begin{array}{l}\text { Hs_NEFH_1_SG QuantiTect } \\
\text { Primer Assay }\end{array}$ & QT00209181 & NM_021076 & 97 \\
\hline MNX1 [Human] & $\begin{array}{l}\text { Hs_MNX1_vb.1_SG Quanti- } \\
\text { Tect Primer Assay }\end{array}$ & QT02407384 & NM_005515 & 130 \\
\hline RPL13A [Human] & $\begin{array}{l}\text { Hs_RPL13A_1_SG Quanti- } \\
\text { Tect Primer Assay }\end{array}$ & QT00089915 & NM_012423 & 161 \\
\hline
\end{tabular}

Table 5. Primers used for real-time RT-PCR.

\begin{tabular}{|l|l|l|l|l|}
\hline \multicolumn{2}{|l|}{ Reaction detail } & Real-time PCR schedule \\
\hline Component & Volume & Step & Temperature & Time \\
\hline SYBR Green I Master Mix & $5 \mu \mathrm{L}$ & Initial denaturation & $95^{\circ} \mathrm{C}$ & $15 \mathrm{~min}$ \\
\hline Diluted cDNA (1:10) & $1 \mu \mathrm{L}$ & Denaturation at & $94^{\circ} \mathrm{C}$ & $15 \mathrm{~s}$ \\
\hline Related primer & $1 \mu \mathrm{L}$ & Annealing temperature & $60^{\circ} \mathrm{C}$ & $30 \mathrm{~s}$ \\
\hline dH2O & $3 \mu \mathrm{L}$ & Extension & $72^{\circ} \mathrm{C}$ & $30 \mathrm{~s}$ \\
\hline & Total $10 \mu \mathrm{L}$ & & & \\
\hline
\end{tabular}

Table 6. Reaction conditions of real-time PCR.

change was calculated relative to RPL13A based on relative quantitation evaluation via the $\Delta \triangle \mathrm{CT}$ method, using the $2^{-\Delta \Delta \mathrm{CT}}$ relative expression equation. A summary of the different steps of the study is shown in Fig. 1.

Analysis and quantification of neurite extension. Analysis of neurite extension was investigated using an inverted phase-contrast microscope (Olympus, Japan) attached to a digital camera (DP50). For each experimental group, five random representative areas were selected for neurite length measurement using ImageJ software.

Statistical data analysis. Data were analyzed using SPSS 21 software. One-way ANOVA and Dunnett's two-tailed t-test (DUNNETT) were employed to evaluate the statistical significance of differences between the control and all experimental groups.

Ethics declarations. Ethical approval for collecting biopsy disposal of patients human endometrial was obtained from the Ethics Committee of Tehran University of Medical Sciences (code: IR.TUMS.REC.1394.1137). An informed consent was obtained from patients/legal guardians according to Tehran University of Medical Sciences guidelines. All methods were performed in accordance with the relevant guidelines and regulations.

\section{Results}

Characterization of hEnSCs derived from endometrium. The hEnSCs were positive for mesenchymal stem cell markers CD44 (98.5\%), CD90 (98.4\%) and CD105 (98.4\%), endometrial stem cell marker CD146 (89.1\%). hEnSCs were also negative for hematopoietic CD45, CD34, and endothelial CD31 markers (Fig. 2a).

Cell GFP transduction. Two types of cells, HEK293-T, and hEnSCs were labeled. As shown in Fig. 2b, cells were effectively transduced by GFP-encoding lentiviral particles. The GFP-positive cells were observed by fluorescent phase-contrast microscopy and used to assess cell adhesion and proliferation within hydrogels.

EpoB-loaded PCL microsphere characterization. Scanning electron microscope. The morphology of the fabricated microspheres was assessed using SEM. SEM images indicated a round shape with some clustering and smooth surface. The diameters of 2.5, 10, and $40 \mathrm{ng} / \mathrm{mg}$ EpoB/PCL microspheres were $3.143 \pm 1.485 \mu \mathrm{m}$, $4.747 \pm 3.434 \mu \mathrm{m}$, and $2.931 \pm 1.543 \mu \mathrm{m}$, respectively. Compared to the EpoB/PCL microspheres, the unloaded microspheres were larger, with a diameter of $6.570 \pm 4.833(\mathrm{P}<0.001)$ (Fig. $3 \mathrm{a}-\mathrm{h})$.

Encapsulation efficiency. The encapsulation efficiencies (EE) for different loading concentrations of EpoB are shown in Table 7. A greater EE was obtained in PCL microspheres with higher EpoB loading levels, indicating that the initial concentration of EpoB can potentially affect EE of EpoB in PCL microspheres using the single emulsion fabrication method. 


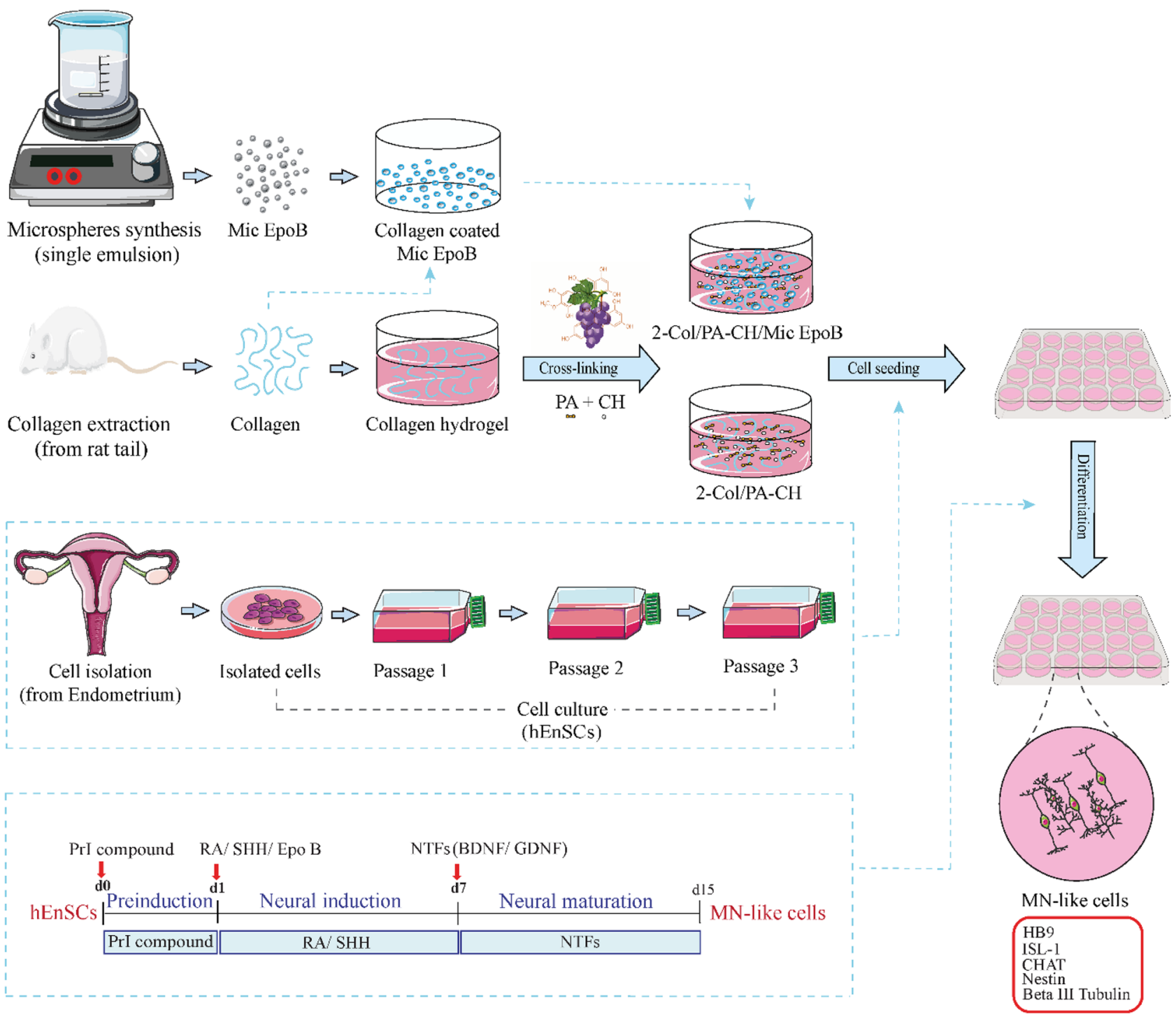

Figure 1. A schematic presentation of different steps of the study, including; EpoB microspheres synthesis using single emulsion, collagen extraction from rat tail, synthesis of collagen hydrogel and its crosslinking using proanthocyanidin from grape seed and calcium hydroxide (PA-CH), cell isolation, and culturing from human endometrium, and a three-step MN-differentiation (during 15 days).

EpoB release. As shown in Fig. 3i, there was a burst release in the initial first $24 \mathrm{~h}$ for all groups, followed by a slower gradual release for 2.5 and $10 \mathrm{ng} / \mathrm{mg}$ EpoB/PCL microspheres, which reached a plateau. However, compared to 2.5 and $10 \mathrm{ng} / \mathrm{mg}$ EpoB/PCL microspheres, the $40 \mathrm{ng} / \mathrm{mg}$ EpoB/PCL microspheres maintained a higher release rate over 21 days, indicating that the release rate is influenced by the amount of EpoB encapsulated in the microspheres. According to the EpoB release results, $2.5 \mathrm{ng} / \mathrm{mg}$ was selected due to its appropriate sustained release dosage for neuronal differentiation.

Proliferation and viability assessment of microspheres. To find the permissible limit, the effect of four different concentrations of unloaded PCL microspheres (unloaded Mic: 5, 10, 15, and $40 \mathrm{mg} / \mathrm{mL}$ ) were assessed for viability and proliferation of hEnSCs during 24, 48, and $72 \mathrm{~h}$ using the MTT assay. The effect of the candidate microsphere $2.5 \mathrm{ng} / \mathrm{mg}$ (Mic EpoB) on hEnSCs was also evaluated by indirect MTT assay for 24, 48, and $72 \mathrm{~h}$ (Fig. 3j). The results indicated no cytotoxicity in all four PCL microsphere concentrations. For Mic EpoB, cell proliferation increased after $24 \mathrm{~h}$. The Mic EpoB cell viability at 48 and $72 \mathrm{~h}$ after treatment was $94.1 \%$ $(\mathrm{P}<0.01)$ and $76.5 \%(\mathrm{P}<0.001)$, respectively.

Cell morphology, attachment, and proliferation. Fluorescent microscopy. Collagen hydrogels improved adhesion and proliferation of HEK293-T (as a typical well-transected GFP cell) and hEnSCs-GFP. As shown in Figs. 4 and 5, the effect of hydrogel fabricated using $2 \mathrm{mg} / \mathrm{mL}$ collagen was more prominent on cell proliferation compared with hydrogel fabrication using $4 \mathrm{mg} / \mathrm{mL}$ collagen. Furthermore, among different 


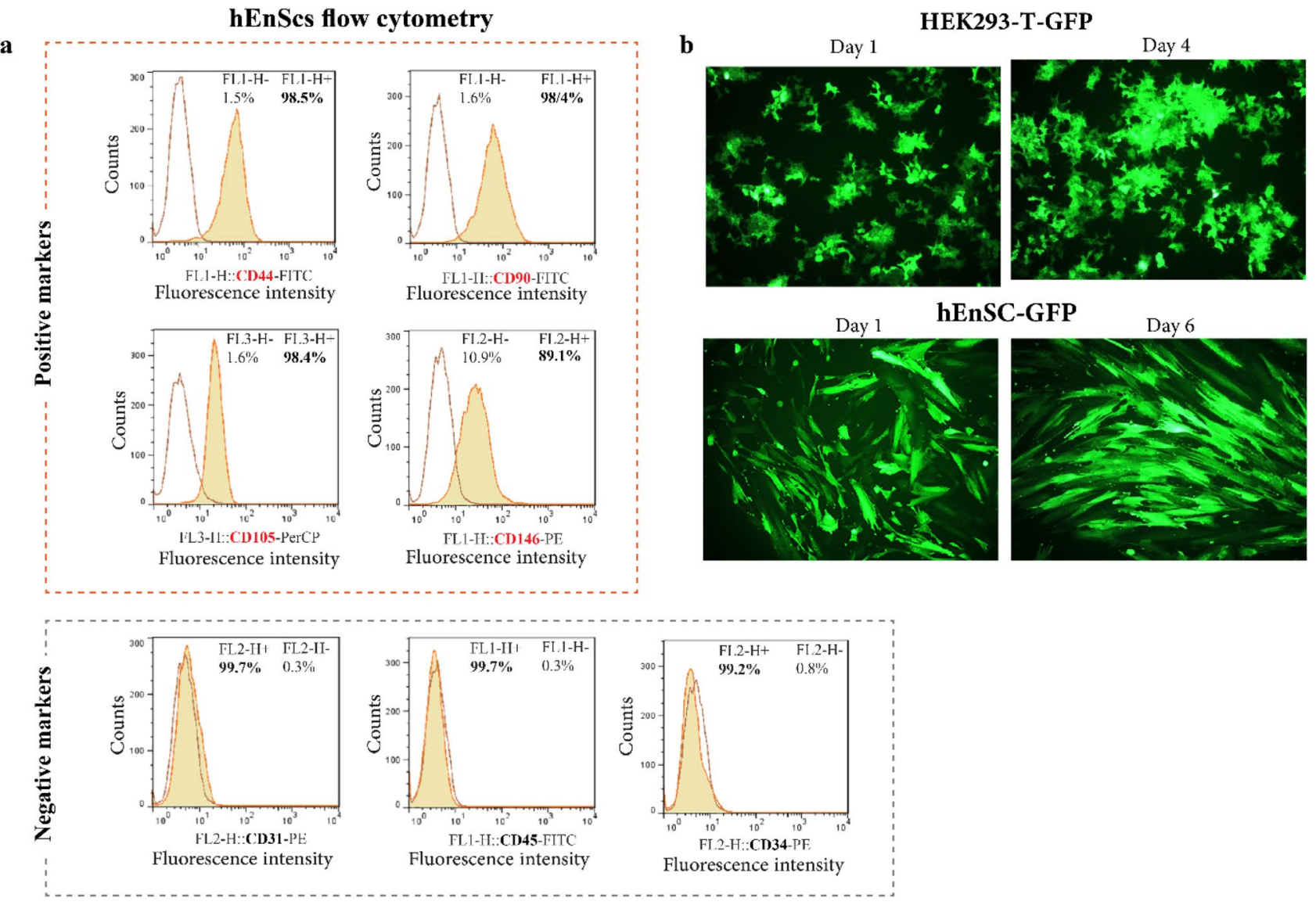

Figure 2. Characterization of cell markers for hEnSCs and verification of GFP-labeling. (a) The results of flow cytometric assessment of hEnSCs at passage three, isolated from the endometrial biopsy. Dark red lines display isotype control (negative control). hEnSCs were positive for mesenchymal stem cell markers CD44 (98.5\%), CD90 (98.4\%), and CD105 (98.4\%), endometrial stem cell marker CD146 (89.1\%), shown as a right shift of the fluorescent intensity peak. hEnSCs were also negative for hematopoietic CD45, CD34, and endothelial CD31 markers (no shift of the fluorescent peak was observed). (b) HEK293-T and hEnSCs transduction with GFPexpressing lentiviral vectors. To confirm GFP expression, the labeled HEK293-T and hEnSCs were monitored with a fluorescent microscopy.

groups, the $0.5 \% \mathrm{PA}-\mathrm{CH}$ hydrogel had the greatest cell proliferation compared to other PA-crosslinked collagen hydrogels in both $2 \mathrm{mg} / \mathrm{mL}$ and $4 \mathrm{mg} / \mathrm{mL}$ collagen concentrations (i.e., 2-Col/PA-CH and 4-Col/PA-CH). Since the 2-Col/PA-CH hydrogel had a more prominent effect on cell proliferation compared to 4-Col/PA-CH, this formulation was selected as the optimized hydrogel for further experiments.

Scanning electron microscope (SEM). SEM images of hEnSCs cultured on collagen, 2-Col/PA-CH, and 2-Col/ PA-CH/Mic EpoB hydrogels indicated cell-scaffold interactions and cell attachment on hydrogel scaffolds $48 \mathrm{~h}$ after cell seeding (Fig. $6 \mathrm{a}-\mathrm{c}, \mathrm{e})$. The interconnected porosity and surface morphology of the hydrogel scaffolds was revealed by SEM. In the 2-Col/PA-CH/Mic EpoB hydrogel, the EpoB microspheres were visible and detected (Fig. 6d,e). The 2-Col/PA and 2-Col/PA-CH hydrogels showed more fibrous and regular structure compared to collagen (Fig. $6 \mathrm{f}-\mathrm{h}$ ), and the 2-Col/PA-CH hydrogel indicated a smooth surface morphology.

Hydrogel biodegradation. The degradation of different hydrogel formulations, including collagen, 2-Col/ $\mathrm{PA}-\mathrm{CH}$, and 2-Col/PA-CH/Mic EpoB, during 14 days of incubation in DMEM-F12 medium at $37^{\circ} \mathrm{C}$ was evaluated (Fig. 7a). The degradation degree of collagen hydrogel was higher than the other two groups (i.e., 2-Col/ PA-CH, and 2-Col/PA-CH/Mic EpoB). Adding of collagen-coated Mic EpoB and PA-CH as a cross-linker increased the stability of the collagen hydrogel. Furthermore, 2-Col/PA-CH/Mic EpoB showed slower degradation and higher stability compared with 2-Col/PA-CH.

Hydrogel swelling. The swelling degree of collagen, 2-Col/PA-CH, and 2-Col/PA-CH/Mic Epo B hydrogels in DMEM-F12 was calculated until 96 h (Fig. 7b). The swelling degrees were as follow:

$$
\text { 2-Col/PA-CH/Mic Epo > collagen > 2-Col/PA-CH. }
$$



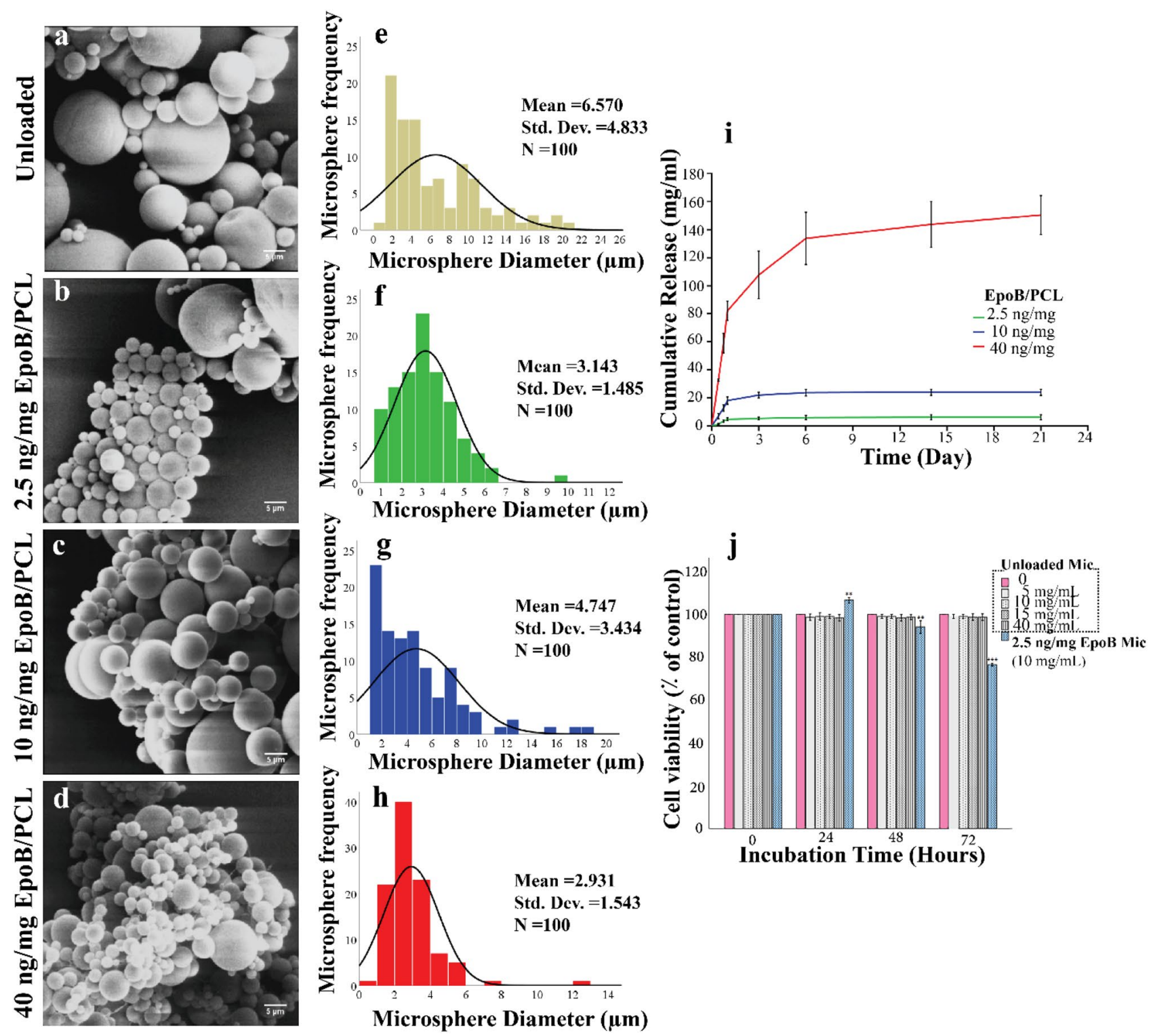

Figure 3. Characterization of microspheres. Scanning electron microscopy (SEM) and characterization of unloaded, 2.5, 10, and $40 \mathrm{ng} / \mathrm{mg}$ EpoB/PCL microspheres. (a-d) SEM shows smooth morphology and some microsphere clustering. (e-h) Particle size distribution histogram indicating expected particle size diameters (Sample size $\mathrm{n}=100$ ). (i) The cumulative release profile of 2.5, 10, and $40 \mathrm{ng} / \mathrm{mg}$ EpoB/PCL microspheres over 21 days (7-time points). Sample size $\mathrm{n}=3$. (j) The effect of $2.5 \mathrm{ng} / \mathrm{mg}$ EpoB Mic and different concentrations of PCL microspheres (unloaded Mic) on cell viability of hEnScs. Data are displayed as the percentage of cell viability in three independent tests, with each test having three individual samples. Cell viability graphs were compiled using SPSS 21 (clustered bar, summaries for groups of cases). (Error bars: \pm 1 SD). P values were assessed with SPSS 21, using one-way ANOVA and DUNNETT test. The effect of all samples was compared to 0 (control). ${ }^{\star} \mathrm{P}<0.05,{ }^{* *} \mathrm{P}<0.01,{ }^{* *} \mathrm{P}<0.001$.

\begin{tabular}{|l|l|}
\hline EpoB concentration added & Encapsulation efficiency \pm SD (\%) \\
\hline $2.5 \mathrm{ng} / \mathrm{mg} \mathrm{EpoB} / \mathrm{PCL}$ & $83 \pm 1$ \\
\hline $10 \mathrm{ng} / \mathrm{mg} \mathrm{EpoB} / \mathrm{PCL}$ & $88.9 \pm 0.5$ \\
\hline $40 \mathrm{ng} / \mathrm{mg} \mathrm{EpoB} / \mathrm{PCL}$ & $93.9 \pm 0.3$ \\
\hline
\end{tabular}

Table 7. Encapsulation efficiencies for different drug loading. Sample size $n=3, P<0.001$. 
a
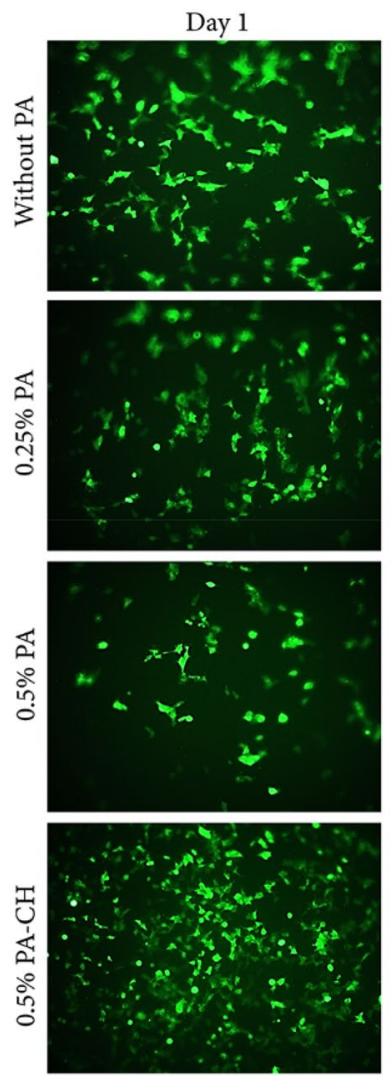

$2 \mathrm{mg} / \mathrm{mL}$ Collagen hydrogel
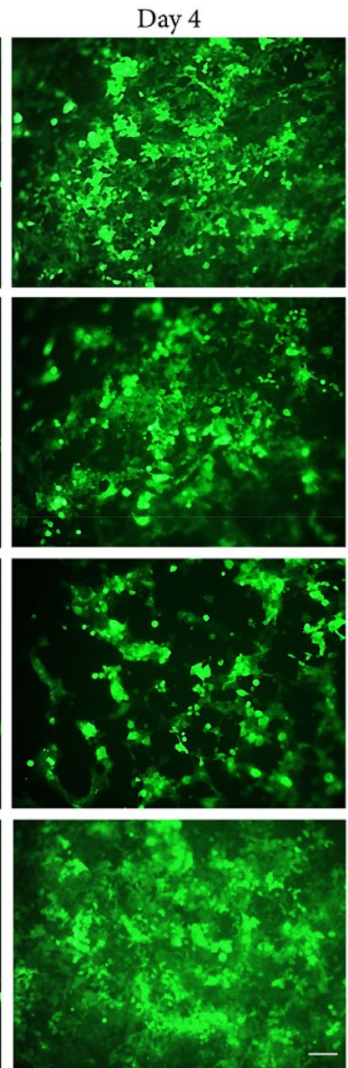

$\mathrm{b}$
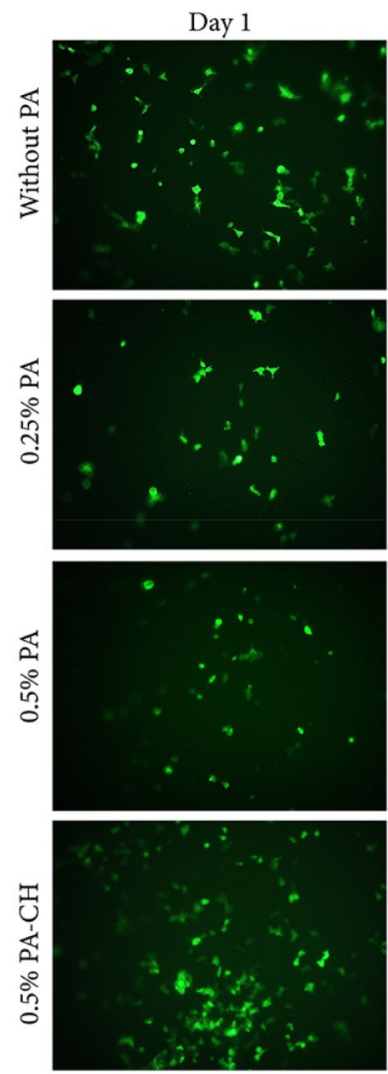

Figure 4. HEK293-T-GFP morphology, adhesion, and proliferation within collagen hydrogels. The HEK293T-GFP adhered to (a) $2 \mathrm{mg} / \mathrm{mL}$ and (b) $4 \mathrm{mg} / \mathrm{mL}$ collagen hydrogel concentrations and all cross-linked collagen hydrogels (using 0.25\% PA, 0.5\% PA and 0.5\% PA-CH). Over time, more GFP-positive cells were observed, indicating that the proliferated cells were GFP positive, as well. Cell proliferation was more prominent in hydrogels fabricated using $2 \mathrm{mg} / \mathrm{mL}$ collagen.

The results showed that adding PA-CH as cross-linker causes a decrease in the swelling degree of collagen. However, the addition of coated collagen microspheres to collagen gel increased the swelling degree of the hydrogel. The consistency in cross-linked collagen hydrogels is presented in Fig. 7c.

ATR-FTIR spectroscopy. The ATR-FTIR spectra of PA, collagen, 2-Col/PA, 2-Col/PA-CH are presented in Fig. 7d. The main peaks including amide A $\left(3280-3290 \mathrm{~cm}^{-1}\right)$, amide B $\left(3075-3085 \mathrm{~cm}^{-1}\right)$, amide I (1635$\left.1656 \mathrm{~cm}^{-1}\right)$, amide II $\left(1549-1566 \mathrm{~cm}^{-1}\right)$, amide III $\left(1174-1177 \mathrm{~cm}^{-1}\right)$, aliphatic C-H bond $\left(2925-2942 \mathrm{~cm}^{-1}\right)$, $\mathrm{CH}_{2}$ bending (1397-1401 $\mathrm{cm}^{-1}$ ) were detected and pointed out by arrows and dash lines. Additionally, to enhances the separation of overlapping peaks, second-derivative spectrum in the amide B region was achieved via irAnalyze software, showing secondary structure conformational changes in the two cross-linked hydrogels scaffold (2-Col/PA and 2-Col/PA-CH) compared to the collagen (uncross-linked) hydrogel scaffold (Fig. 7e).

The effect of 3D collagen hydrogel and EpoB release on differentiation of hEnSCs into motor neuron-like cells. Immunofluorescence staining. After 15 days of $\mathrm{MN}$-induction, the morphology of hEnSCs changed from a fibroblast-like shape to a bipolar and round cell body shape with neurites. The neuron-like morphology was observed using an inverted phase-contrast microscope (Olympus, Japan). IF staining results showed up-regulation of the MN markers ISL-1, CHAT, and HB9 in all three experimental groups, but no expression in the control group (Fig. 8a).

Differentiation rate was investigated by counting each positive cell marker (beta-tubulin III, ISL-1, CHAT, NES, HB9) as a percentage of the total number of DAPI-stained cells. The level of positive MN markers expression in cells seeded on 2-Col/PA-CH/Mic EpoB group was significantly higher $(\mathrm{P}<0.001)$ than the other two groups (i.e., TCP, and 2-Col/PA-CH), except for NES. The positive marker expression of different evaluated markers in TCP, 2-Col/PA-CH, and 2-Col/PA-CH/Mic EpoB is shown below, respectively. Quantitative results are also shown in Fig. 8 b.

- beta-tubulin III (89\%, 92\%, 98\%,)

- $\operatorname{ISL}-1(83 \%, 88 \%, 98 \%)$

- $\operatorname{CHAT}(80 \%, 85 \%, 97 \%)$ 
$2 \mathrm{mg} / \mathrm{mL}$ Collagen hydrogels

$\mathbf{a}$
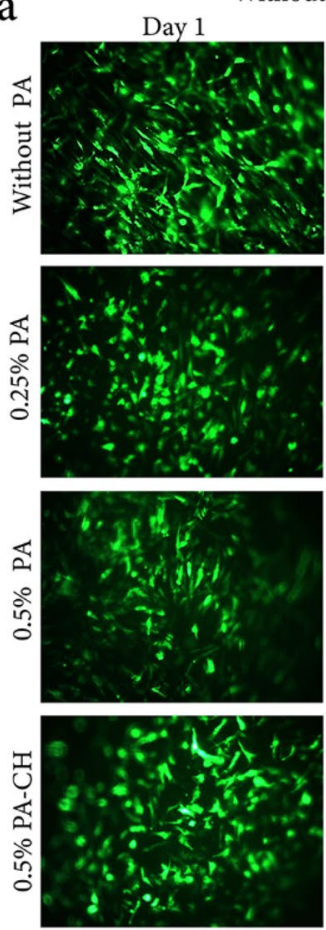

Without Mic EpoB (day 6)

b
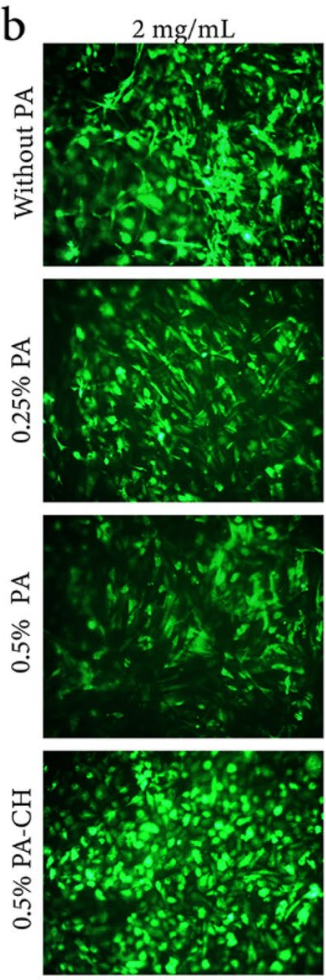

Day 6
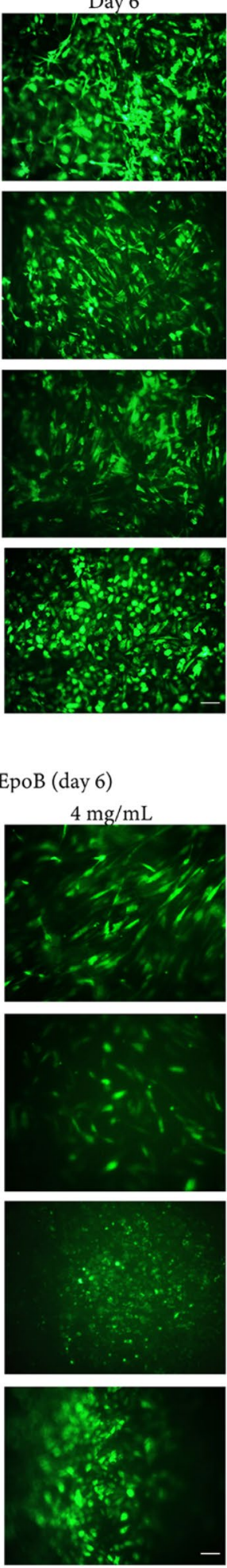
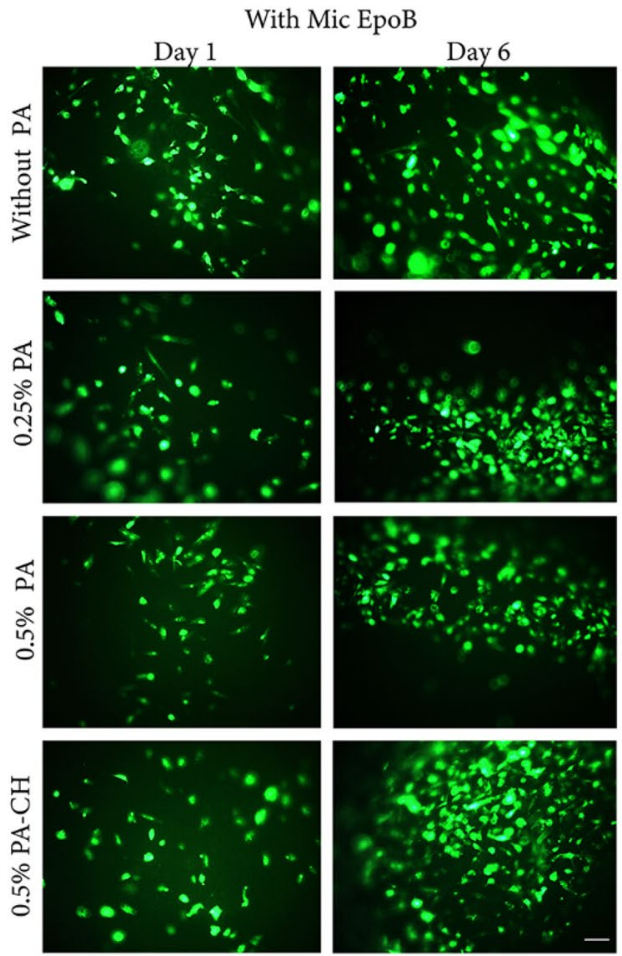

With Mic EpoB (day 6)
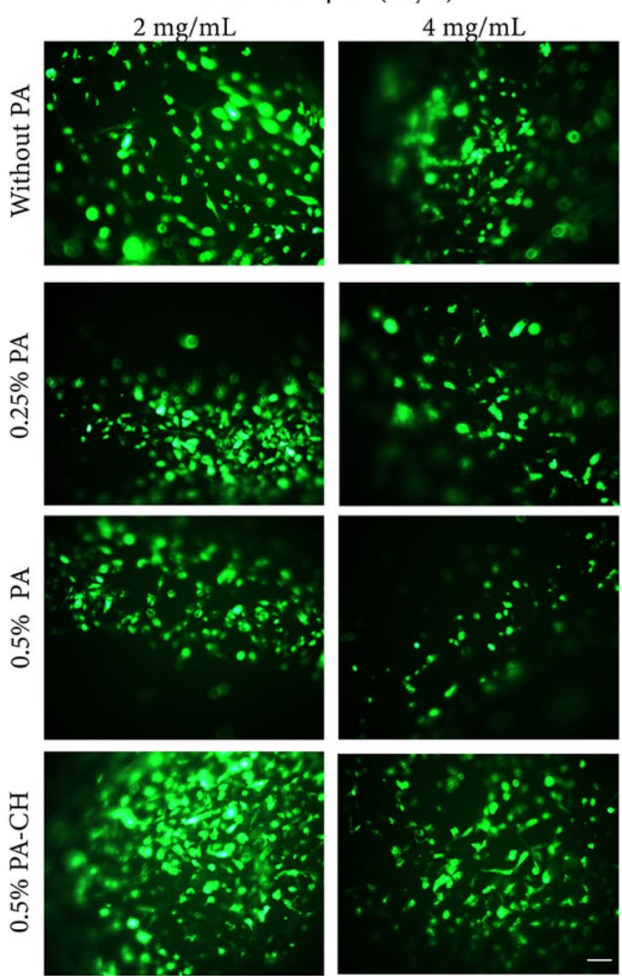

Figure 5. Adhesion and proliferation of hESCs-GFP within collagen hydrogels before and after cross-linking using different concentrations of PA (0.25\% PA, 0.5\% PA, and 0.5\% PA-CH). (a) Collagen hydrogels were fabricated using $2 \mathrm{mg} / \mathrm{mL}$ collagen with or without Mic EpoB at day 1 and day 6, (b) and a comparison between hydrogels was performed using different collagen concentrations (i.e., $2 \mathrm{mg} / \mathrm{mL}$ and $4 \mathrm{mg} / \mathrm{mL}$ ) with or without Mic EpoB at day 6 of culture. 

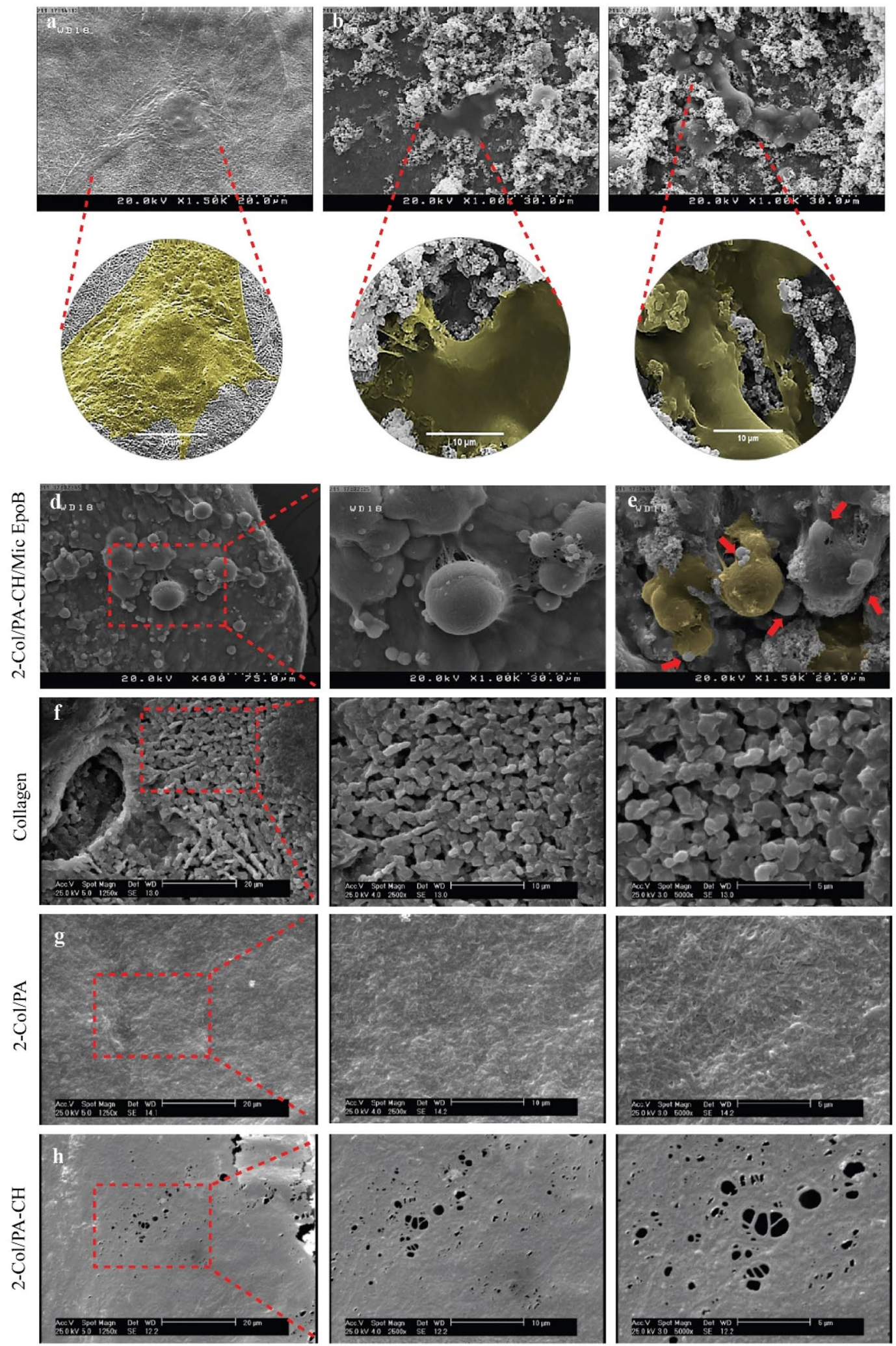

Figure 6. Cell attachment and surface morphology of different collagen hydrogel groups. Scanning electron micrographs of hEnSCs attachment on (a) collagen, (b) 2-Col/PA-CH, and (c) 2-Col/PA-CH/Mic EpoB hydrogels $48 \mathrm{~h}$ after cell seeding. Micrographs show hydrogel with cells at $\times 1000$ and $\times 3000$ magnifications (pseudo-colored). Scanning electron micrographs of different collagen hydrogel groups (d-h) indicates their surface morphology and interconnected porosity: 2-Col/PA-CH/Mic EpoB (d,e), collagen (f), 2-Col/PA (g), and 2-Col/PA-CH (h). EpoB microspheres were detected in the 2-Col/PA-CH/Mic EpoB hydrogel (d,e). Moreover, the cell attachment (highlighted in yellow) and EpoB microspheres (pointed with red arrows) are displayed in 2-Col/PA-CH/Mic EpoB hydrogel in Figure e. 
$\mathrm{a}$
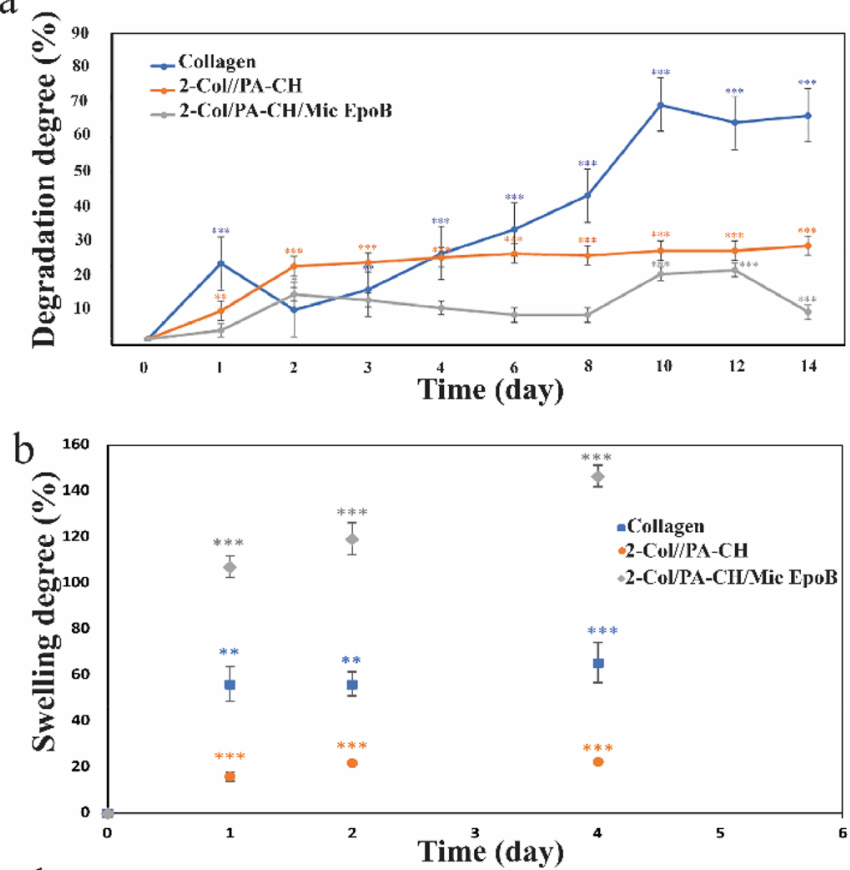

d

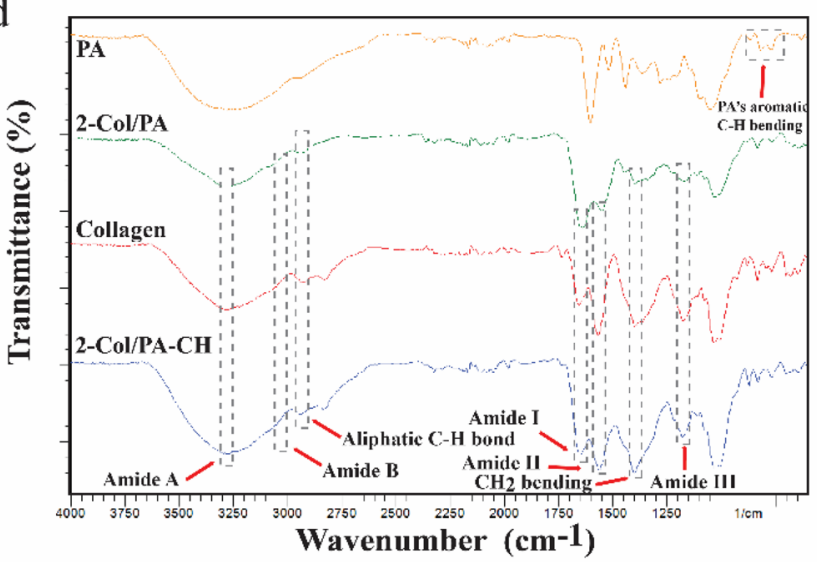

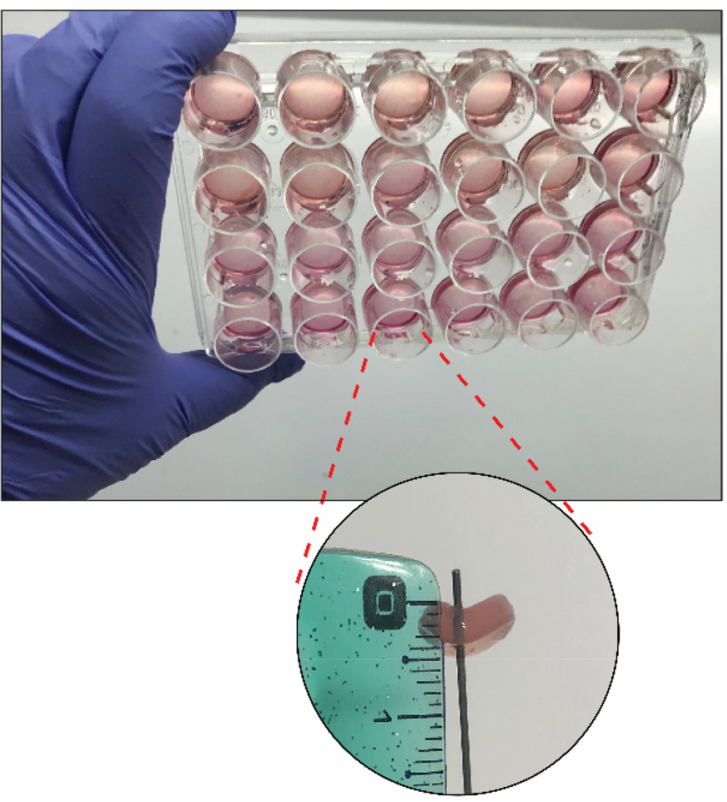

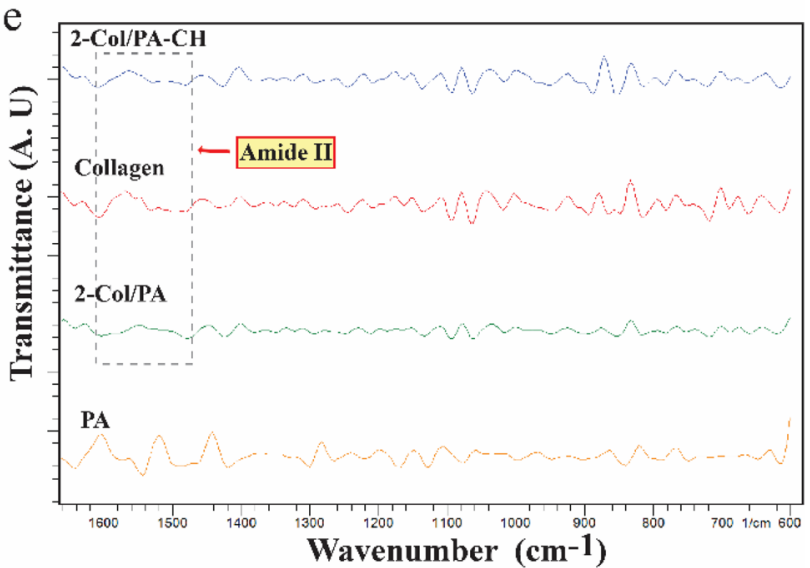

Figure 7. Degradation and swelling degree, and ATR-FTIR spectra of different collagen hydrogel groups. (a) Degradation and (b) swelling degree of collagen, 2-Col/PA-CH (Cross-linked $2 \mathrm{mg} /$ collagen hydrogel with $0.5 \%$ proanthocyanidin and calcium hydroxide), and 2-Col/PA-CH/Mic EpoB (Cross-linked $2 \mathrm{mg} / \mathrm{mL}$ collagen hydrogel with $0.5 \%$ proanthocyanidin and calcium hydroxide and $2.5 \mathrm{ng} / \mathrm{mL}$ Epo B microspheres) hydrogels in DEME-F12 at $37^{\circ} \mathrm{C}$ (The time duration: 14 days for degradation test and 4 days for swelling test). ${ }^{\star} \mathrm{P}<0.05$, ${ }^{*} \mathrm{P}<0.01,{ }^{* *} \mathrm{P}<0.001$. (c) The consistency in cross-linked collagen hydrogels. (d) The ATR-FTIR spectra of $\mathrm{PA}$, collagen, 2-Col/PA, 2-Col/PA-CH and, (e) their second-derivative spectra in the amide $\mathrm{B}$ region. The main peaks are shown by red arrows and gray dash lines. The second-derivative spectra in the amide $\mathrm{B}$ region indicate secondary structure conformational changes in the two cross-linked hydrogels scaffold (2-Col/PA and 2-Col/ PA-CH) compared to the collagen (uncross-linked) hydrogel scaffold.

- $\operatorname{NES}(100 \%, 100 \%, 100 \%)$

- $\operatorname{HB9}(78 \%, 84 \%, 96 \%)$

Molecular analysis using real-time-PCR. After 15 days of cell induction, real-time RT-PCR was performed to compare the fold-change of RNA expressions of HB9, ISL-1, NES, and NEFH in three experimental groups, including TCP, 2-Col/PA-CH, 2-Col/PA-CH/Mic EpoB and control (undifferentiated hEnSCs) (Fig. 8c). The real-time-RT-PCR results indicated that the level of HB9, ISL-1, NES, and NEFH was significantly up-regulated in all three induced $\mathrm{hEnSCs}$ groups $(\mathrm{P}<0.001, \mathrm{P}<0.01)$. Between the three experimental groups, the 2 - $\mathrm{Col} /$ PA-CH/Mic EpoB hydrogel had the highest expression level of HB9 and ISL-1 as MN markers (12.4- and 12-fold change, respectively). The expression of $H B 9$ in the 2-Col/PA-CH/Mic EpoB hydrogel was 4.43- and 4.13-times higher than the TCP and 2-Col/PA-CH hydrogel, respectively (2.8- and 3-fold change, respectively). The expression of ISL-1 in the 2-Col/PA-CH/Mic EpoB hydrogel was 2.4- and 1.71-times higher than the TCP and 2-Col/ 
a

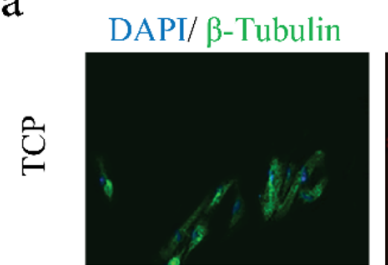

DAPI/ NES
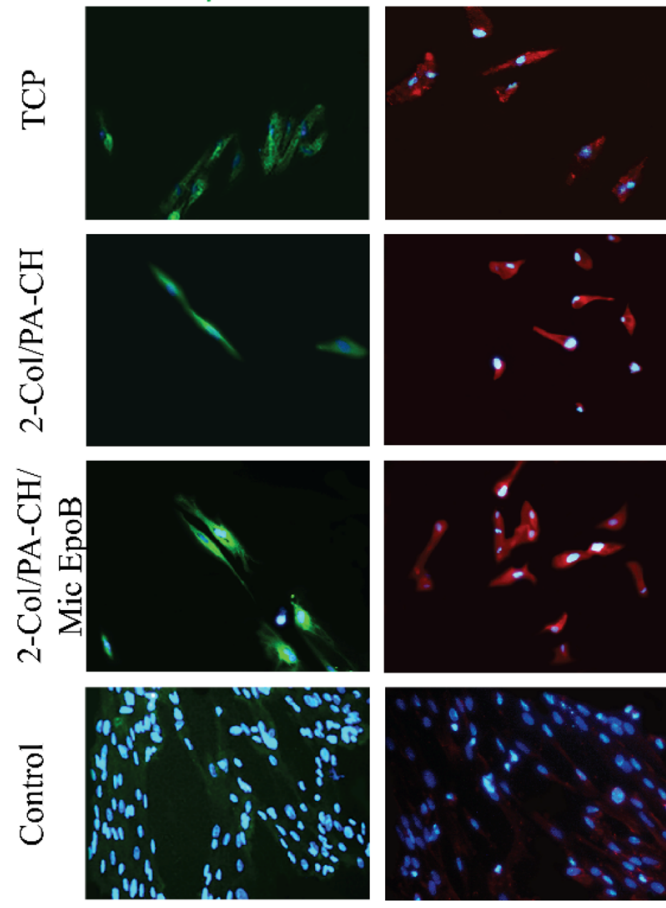

b
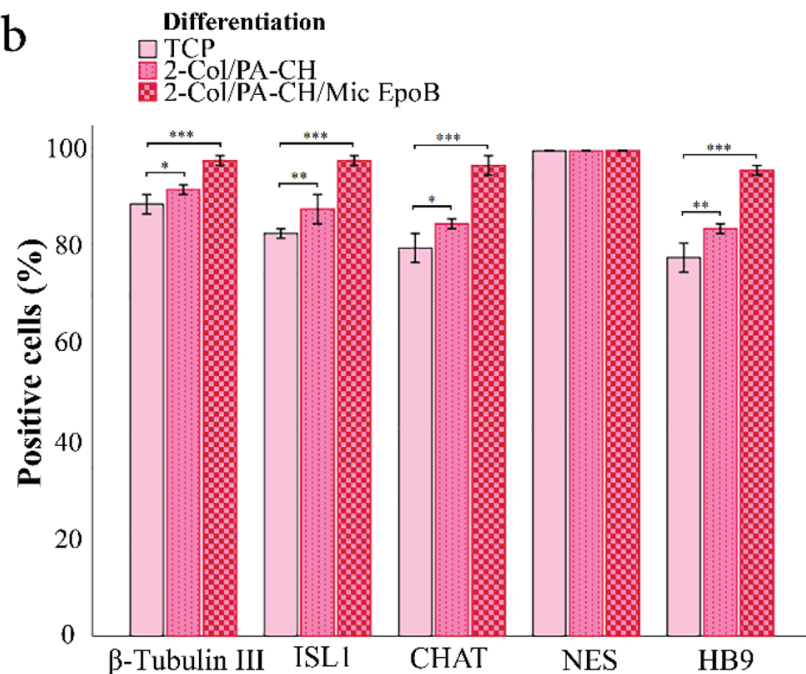

Day 15 of differentiation
DAPI/ ISL-1
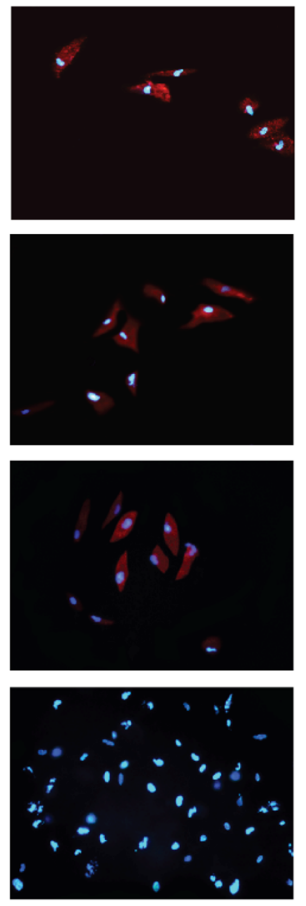

C
DAPI/ CHAT
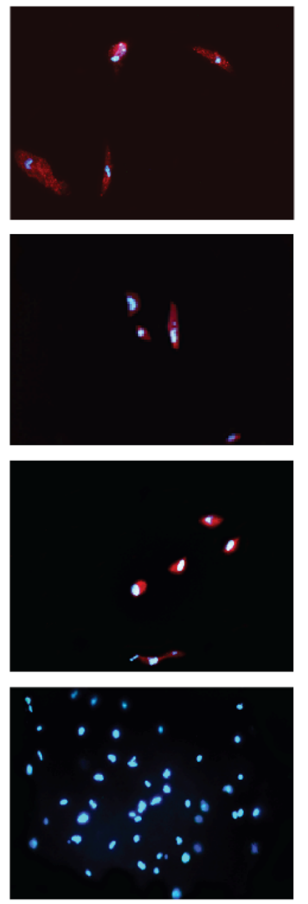

Differentiation
DAPV/ HB9
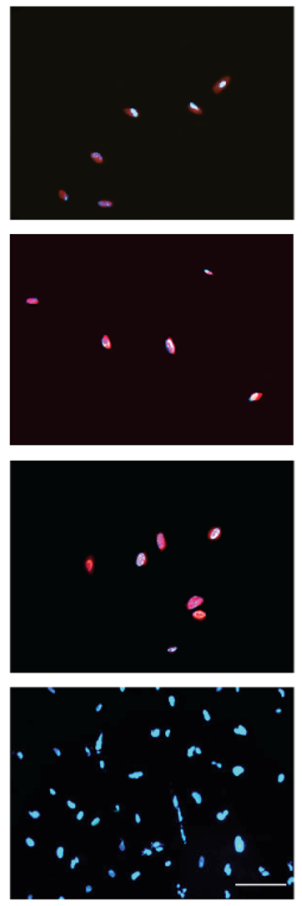

Figure 8. The expression of MN-like cells differentiated from hEnSCs in different groups. (a)

Immunofluorescence images of MN-like differentiated hEnSCs in different groups of TCP, collagen hydrogel without Mic EpoB (2-Col/PA-CH/M), collagen hydrogel with Mic EpoB (2-Col/PA-CH/Mic EpoB), and control (undifferentiated hEnSCs) for beta-III-tubulin, NES, ISL-1, CHAT, and HB9 after 15 days $(\times 20$, Scale bar $100 \mu \mathrm{m}$ ). (b) Expression (ratio of positive cells, \%) of MN markers calculated from three wells (five fields per well). (c) Relative gene expression in three differentiated groups, including TCP, Col without Mic EpoB, Col with Mic EpoB, and control (undifferentiated hEnSCs) after 15 days for NEFH, ISL-1, NES, and HB9. Graphs were generated with SPSS 21 (simple bar, summaries for groups of cases). Data were presented as three independent experiments. (Error bars: \pm 1 SD). The p-values were assessed using SPSS 21, one-way ANOVA, and the DUNNETT test. In part B: Col without Mic EpoB and Col with Mic EpoB groups were compared with TCP: ${ }^{\star} \mathrm{P}<0.05,{ }^{*} \mathrm{P}<0.01,{ }^{* * *} \mathrm{P}<0.001$. In part $\mathrm{C}$ : The effects of three differentiation groups (TCP, col-without Mic EpoB, and col-with Mic EpoB) compared with control group (undifferentiated hEnSCs): ${ }^{\star} \mathrm{P}<0.05$, ${ }^{\star *} \mathrm{P}<0.01$, $* * \star \mathrm{P}<0.001$. 


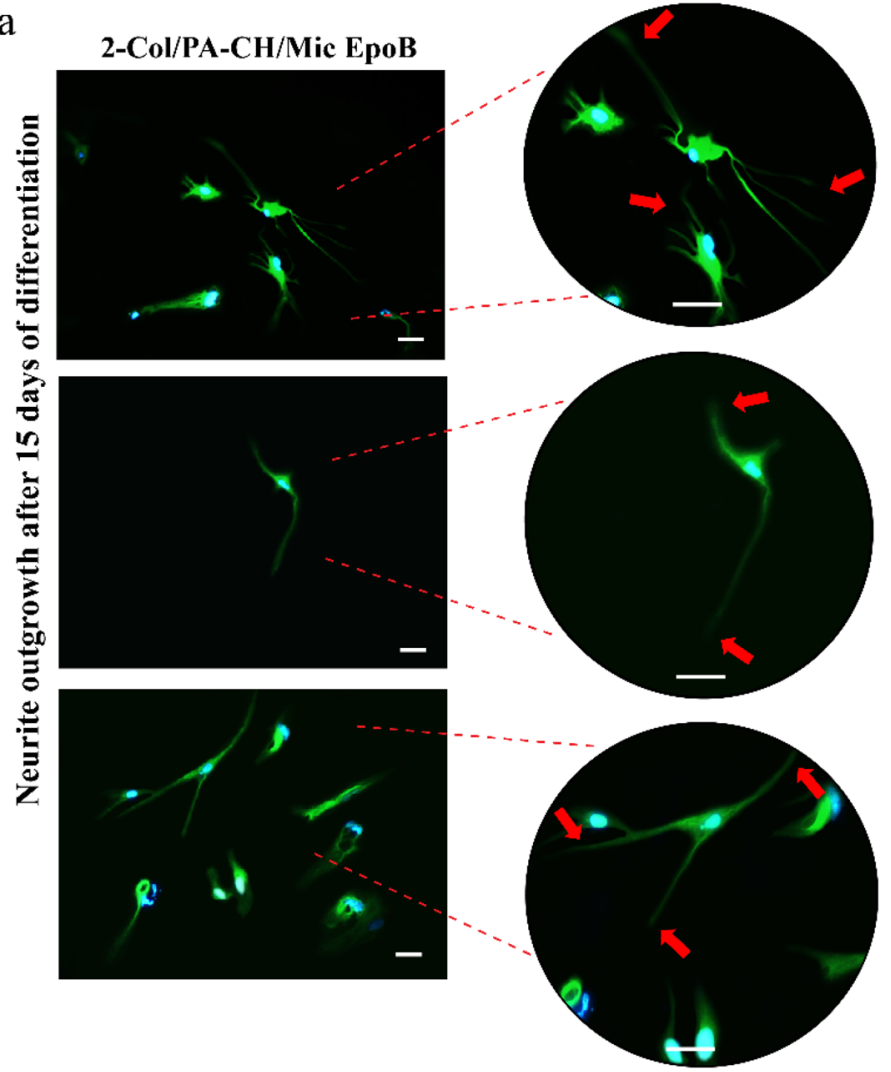

Added EpoB in 2D culture

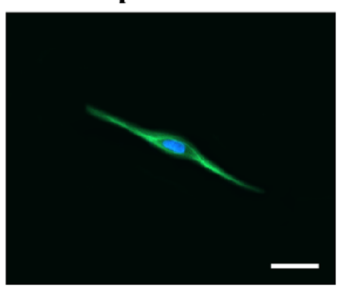

$\mathrm{b}$

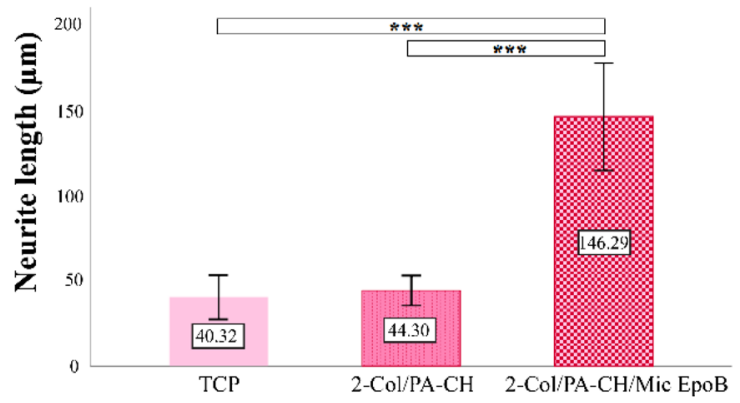

Day 15 of differentiation

Figure 9. Neuronal morphology and neurite outgrowth. (a) Immunofluorescence images indicate neuronal morphology and neurite elongation of MN-like differentiated hEnSCs after 15 days of induction in collagen hydrogel with Mic EpoB (2-Col/PA-CH/Mic EpoB) group. (b) Neurite elongation is shown with red arrows. To display morphology, cells were stained using primary anti-beta III tubulin antibody and secondary Alexa Fluor 488 antibody $(\times 20$ and $\times 40$; Scale bar $100 \mu \mathrm{m})$. Neurite length of MN-like cells in 2-Col/PA-CH/Mic EpoB hydrogel compared to TCP and 2-Col/PA-CH differentiation groups at day 15 after differentiation $\left({ }^{* * *} \mathrm{P}<0.001\right)$.

PA-CH, respectively (5- and 7-fold change, respectively). The NES and NEFH expressions in the 2-Col/PA-CH/ Mic EpoB hydrogel were almost the same as TCP and 2-Col/PA-CH groups.

Neurite extension. The neurite length of the MN-like cells was significantly longer in 2-Col/PA-CH/Mic EpoB hydrogels compared to TCP and 2-Col/PA-CH groups $(\mathrm{P}<0.001)$ after 15 days of MN-induction (Fig. 9).

\section{Discussion}

In recent years, increasing evidence suggests that small molecules are effective chemical agents for cell survival and differentiation, and may be candidates for various interventional therapies ${ }^{60}$. Small molecules often regulate the activity of several transcription factors, which can thereby determine cell fate. Thus, exposing stem cells to small molecules can advance cell differentiation by mimicking tissue microenvironment during organogenesis ${ }^{61,62}$. Ruschel et al. reported low doses of EpoB, known as a small molecule, diminishes fibrotic scar tissue and induces axonal regeneration in vitro in injured cortical neurons of postnatal rats ${ }^{37}$. This study aimed to evaluate the effect of sustained release of EpoB using PCL microspheres embedded in 3D collagen hydrogel for differentiation of hEnSCs into MN-like cells.

Many studies have proposed tissue engineering as a practical approach to repairing various damaged tissues, and nerve tissue engineering is no exception to this rule, especially given the increasing rate of SCI ${ }^{23,63}$. Many combinational approaches have proven advantageous compared with using each method separately. However, these approaches require further elucidation to ensure a meaningful effect compared to their individual usage $\mathrm{e}^{12}$.

It is known that ECMs have active roles in cell survival, neuronal differentiation, and neurite development ${ }^{12}$. Embedding hydrogels alone without any treatment may slightly improve injury outcomes after SCI ${ }^{8}$. However, for the hydrogel approach, it has been shown drug incorporation into hydrogels is necessary for effective healing of the injured environment ${ }^{8,40}$.

In this study, we synthesized EpoB/PCL microspheres to have a sustained release during the MN differentiation process. The results indicated that PCL microspheres mediated the sustained release of EpoB as a microtubule-stabilizing small molecule that enhances differentiation of hEnSCs to MN-like cells and increases axonal elongation. The addition of released EpoB, along with the differentiation protocol, promoted neurite outgrowth 
and neuronal morphology. It also significantly increased the efficiency of motor neuron generation ('96\%), and compared to most recent studies, it gained a higher percentage of motor neurons ${ }^{64,65}$.

PCL was chosen for microsphere synthesis because of its good biocompatibility, low biodegradation, and cost-effectiveness $^{39}$. All four groups of EpoB/PCL microspheres (0, 2.5, 10, and $40 \mathrm{ng} / \mathrm{mg}$ ) were synthesized using a single emulsion technique, and their round shape microspheres with a smooth surface were demonstrated by SEM. Based on the EpoB release test results, the $2.5 \mathrm{ng} / \mathrm{mg} \mathrm{EpoB} / \mathrm{PCL}$ microsphere group was selected for MN differentiation given a more appropriate dose and drug release and normal size distribution. The indirect MTT test also confirmed the suitability of $2.5 \mathrm{ng} / \mathrm{mg}$ EpoB/PCL microsphere for our purposes with cell viability ${ }^{>} 77 \%$ after $72 \mathrm{~h}$.

Recent studies indicate that culturing stem cells in 3D hydrogels improves cell maintenance, expansion, and differentiation by mimicking the native $\mathrm{ECM}^{66,67}$. For neuronal replacement therapies, given that neurons are not capable of dividing, stem cell expansion with hydrogel assistance is essential to achieve a suitable cell number before neuronal differentiation ${ }^{6}$.

Cell attachment to the ECM is crucial for cell differentiation and proliferation via cell anchoring and activation of signaling pathways that can lead to tissue regeneration and development ${ }^{69-71}$. Collagen is a key component of the ECM and is extensively used as a scaffold for its effective properties of improving cell attachment, survival, proliferation, differentiation, and migration ${ }^{72}$. One study also reported that collagen might promote higher survival, adhesion, and proliferation of mesenchymal stem cells ${ }^{73}$. These cell processes are regulated by the interaction of collagen with integrins in cell surface receptors ${ }^{74}$. Moreover, collagen has garnered attention as a delivery system for the sustained release of different drugs and chemical agents ${ }^{75,76}$.

GFP cell culture in the two collagen hydrogel concentrations ( 2 and $4 \mathrm{mg} / \mathrm{mL}$ ) presented a dose-dependent proliferation of hEnSC. The lower concentration, $2 \mathrm{mg} / \mathrm{mL}$, was selected because of its greater potential for cell proliferation and cell connection, which are important for neural differentiation. In line with our study, a previous report indicated that lower concentrations of collagen are more appropriate for neuronal differentiation and neurite outgrowth ${ }^{77}$.

Moreover, adding either PA-CH or PA to the collagen hydrogel increased its stability during the 15-day differentiation process by decreasing the hydrogel's degradation degree. However, hydrogels cross-linked with PA-CH showed a greater cell proliferation than PA alone. In addition, cross-linking the collage hydrogel also decreased the swelling degree of the hydrogel. Interestingly, the 2-Col/PA-CH/Mic EpoB had a slower degradation degree than the collagen and 2-Col/PA- $\mathrm{CH}$ groups, which can be attributed to the interactions between PCL microspheres and the collagen hydrogel. The 2-Col/PA-CH/Mic EpoB had a higher swelling ratio than the collagen and 2-Col/PA-CH hydrogels. All three groups showed interconnected porous, proper cell-scaffold integration and cell attachment.

Immunofluorescence staining indicated that the beta III-tubulin marker was increased in all three differentiation groups (i.e., TCP, 2-Col/PA-CH, and 2-Col/PA-CH/Mic EpoB). In agreement with previous reports, undifferentiated hEnSCs and other sources of human MSCs have a spontaneous expression of this marker ${ }^{78}$, demonstrating that it is possible for MSCs such as hEnSCs to undergo neuronal differentiation. Furthermore, other studies have shown that hEnSCs can induce spinal motor neuron generation during development by upregulating dopamine ${ }^{79}$. However, compared to the differentiation groups, the undifferentiated hEnSCs in our study had a lower beta III-tubulin expression. hEnSCs also spontaneously express NES. Thus, both NES and beta III-tubulin markers show hEnSCs to be a suitable source for neuronal differentiation and spinal cord restoration.

Real-time RT-PCR determined significant gene up-regulation of NEFH, NES, ISL-1, and HB9 after 15 days of induction. Higher gene expression of $I S L-1$ and $H B 9$ in the 2-col/PA-CH/MicEpoB group compared to the other two differentiation groups showed that incorporation of EpoB microspheres in the collagen hydrogels may significantly increase the MN differentiation efficacy of hEnSCs.

The results show that the release of EpoB from microspheres, in addition to RA and SHH, increase HB9 gene expression $^{80,81}$, and can significantly enhance the gene expression of $H B 9$ and also ISL-1, which are two crucial regulators of mature motor neurons ${ }^{82,83}$. Moreover, among the other two groups, the 2-Col/PA-CH group demonstrated higher $I S L-1$ gene expression.

The percentage of HB9 and ISL-1 positive cells is known to be an indicator of motor neuron differentiation efficiency ${ }^{84}$. The three differentiation groups, 2-Col/PA-CH/Mic EpoB, 2-Col/PA-CH, and TCP, demonstrated $94 \%, 84 \%$, and $78 \%$ HB9 positive cells, while this was $98 \%, 88 \%$, and $83 \%$ for ISL-1, respectively. This confirms the higher $\mathrm{MN}$-differentiation efficiency of the 2-Col/PA-CH/Mic EpoB group compared to the other two differentiation groups. This is while a previous study indicated $11.7 \%$ and $23.7 \%$ positive cells for HB9 and ISL-1, respectively, for MN-like cells derived from tonsil mesenchymal stem cells (T-MSCs). Also, other studies show $35-46 \%$ and $70-90 \%$ positive cells for HB9 and ISL-1, respectively, in MN-like cells derived from induced pluripotent stem cells (iPSCs) ${ }^{85-87}$.

Furthermore, the neurite length of MN-like cells in the 2-Col/PA-CH/Mic EpoB group increased remarkably to $146 \mu \mathrm{m}$, which is more than three times longer compared to the other two groups without Epo B microspheres (2-Col/PA-CH, and collagen groups). Recently, it was reported that acellularized spinal cord scaffolds incorporating $\mathrm{bpV}(\mathrm{pic}) / \mathrm{PLGA}$ microspheres promote axonal regeneration by about $45 \mu \mathrm{m}^{88}$.

Another study indicated that adding $3 \mathrm{nM}$ of paclitaxel as an MSA can enhance neurite length of mature rat retinal ganglion cells (RGCs) by $40 \mu \mathrm{m}$ while using $10 \mathrm{nM}$ paclitaxel significantly decreases neurite outgrowth ${ }^{89}$. This shows that paclitaxel has less of an effect on neurite outgrowth than EpoB. Additionally, compared with paclitaxel, EpoB has a smaller molecular size, higher solubility, and the capability to pass the blood-brain barrier $(\mathrm{BBB})^{90,91}$. It is worth noting that EpoB can be effective for axon elongation and MN-differentiation, despite the presence of the neurite outgrowth inhibitor A, which is known to be an axonal inhibitor in $\mathrm{SCI}^{23,26}$.

One proposed method of increasing neurite outgrowth in recent years is electrical stimulation ${ }^{92-94}$. A study reported that the neurite length of PC12 cells via gold-nanoparticle after electrical stimulation (ES) was $120 \mu \mathrm{m}^{95}$. 
Another study reported, the final neurite length of the primary prefrontal cortex (PFC) in collagen 3D cultures with ES to be $\sim 110 \mu \mathrm{m}$, compared to the control wild-type where only $\sim 10 \mu \mathrm{m}$ of elongation was observed ${ }^{96}$. Thus, our results indicate that the fabricated 2-Col/PA-CH/Mic EpoB hydrogel achieved a higher neurite elongation than the mentioned studies.

While understanding the exact mechanism of EpoB and adapting it to the complex mechanism of SCI yet need to achieve a clear vision, today its role in stem cell differentiation and SCI has garnered attention, and our study demonstrated the enhanced MN differentiation efficiency of hEnSCs and neurite growth by 3D crosslinked collagen hydrogel containing EpoB-loaded microspheres which can be used as a combinatorial approach for MN-diseases modeling and a future aid in SCI repair.

\section{Conclusion}

To our knowledge, this is the first time that ultra-low doses of EpoB loaded microspheres have been synthesized for the purpose of MN differentiation from hEnSCs. Our study demonstrates that incorporation of EpoB microspheres with collagen hydrogel can significantly increase the MN differentiation efficiency of hEnSCs by up-regulating $I S L-1$ and HB9, known as mature motor neuron key markers. Moreover, our results showed that the addition of EpoB microspheres significantly enhances neurite growth during $\mathrm{MN}$ differentiation. Utilizing proanthocyanidin and calcium hydroxide as cross-linkers significantly reduces the degradation degree of the 3D collagen hydrogel and provides an appropriate stable ECM for supporting cell attachment, proliferation, and differentiation. Our findings emphasize the active role that $3 \mathrm{D}$ cross-linked collagen hydrogels containing EpoB-loaded microspheres for nerve tissue engineering and the potential of using combinatorial approaches to overcome the limitations of individual methods for SCI repair.

\section{Data availability}

The datasets used and/or analyzed during the current study are available on reasonable request.

Received: 19 July 2021; Accepted: 22 October 2021

Published online: 05 November 2021

\section{References}

1. Jazayeri, S. B., Beygi, S., Shokraneh, F., Hagen, E. M. \& Rahimi-Movaghar, V. Incidence of traumatic spinal cord injury worldwide: A systematic review. Eur. Spine J. 24, 905-918 (2015).

2. James, S. L. et al. Global, regional, and national burden of traumatic brain injury and spinal cord injury, 1990-2016: A systematic analysis for the Global Burden of Disease Study 2016. Lancet Neurol. 18, 56-87 (2019).

3. Hassannejad, Z. et al. Axonal degeneration and demyelination following traumatic spinal cord injury: A systematic review and meta-analysis. J. Chem. Neuroanat. 97, 9-22 (2019).

4. Johnson, P. J., Tatara, A., Shiu, A. \& Sakiyama-Elbert, S. E. Controlled release of neurotrophin-3 and platelet-derived growth factor from fibrin scaffolds containing neural progenitor cells enhances survival and differentiation into neurons in a subacute model of SCI. Cell Transplant. 19, 89-101 (2010).

5. Nikbakht-Nasrabadi, A., Mohammadi, N., Yazdanshenas, M. \& Shabany, M. Toward overcoming physical disability in spinal cord injury: A qualitative inquiry of the experiences of injured individuals and their families. BMC Neurol. 19, 1-8 (2019).

6. Noorimotlagh, Z., Babaie, M., Safdarian, M., Ghadiri, T. \& Rahimi-Movaghar, V. Mechanisms of spinal cord injury regeneration in zebrafish: A systematic review. Iran. J. Basic Med. Sci. 20, 1287 (2017).

7. Rolls, A., Shechter, R. \& Schwartz, M. The bright side of the glial scar in CNS repair. Nat. Rev. Neurosci. 10, 235 (2009).

8. Johnson, C. D., D’Amato, A. R. \& Gilbert, R. J. Electrospun fibers for drug delivery after spinal cord injury and the effects of drug incorporation on fiber properties. Cells Tissues Organs 202, 116-135 (2016).

9. Shabany, M. et al. Reliability and validity of the Persian version of the spinal cord injury lifestyle scale and the health behavior questionnaire in persons with spinal cord injury. Spinal Cord 56, 509-515 (2018).

10. Gao, S. et al. Differentiation of human adipose-derived stem cells into neuron/motoneuron-like cells for cell replacement therapy of spinal cord injury. Cell Death Dis. 10, 1-15 (2019).

11. Hassannejad, Z. et al. The fate of neurons after traumatic spinal cord injury in rats: A systematic review. Iran. J. Basic Med. Sci. 21, $546(2018)$.

12. Griffin, J. M. \& Bradke, F. Therapeutic repair for spinal cord injury: Combinatory approaches to address a multifaceted problem. EMBO Mol. Med. 12, e11505 (2020).

13. Farzin, A. et al. A facile two step heat treatment strategy for development of bioceramic scaffolds for hard tissue engineering applications. Mater. Sci. Eng. C 105, 110009 (2019).

14. Khanmohammadi, M., Nemati, S., Ai, J. \& Khademi, F. Multipotency expression of human adipose stem cells in filament-like alginate and gelatin derivative hydrogel fabricated through visible light-initiated crosslinking. Mater. Sci. Eng. C 103, 109808 (2019).

15. Bordbar, S. et al. Production and evaluation of decellularized extracellular matrix hydrogel for cartilage regeneration derived from knee cartilage. J. Biomed. Mater. Res. Part A 108, 938-946 (2020).

16. Astaneh, M. E. et al. Chitosan/gelatin hydrogel and endometrial stem cells with subsequent atorvastatin injection impact in regenerating spinal cord tissue. J. Drug Deliv. Sci. Technol. https://doi.org/10.1016/j.jddst.2020.101831 (2020).

17. Zahiri, M. et al. Encapsulation of curcumin loaded chitosan nanoparticle within poly ( $\varepsilon$-caprolactone) and gelatin fiber mat for wound healing and layered dermal reconstitution. Int. J. Biol. Macromol. 153, 1241-1250 (2019).

18. Hasanzadeh, E. et al. Preparation of fibrin gel scaffolds containing MWCNT/PU nanofibers for neural tissue engineering. J. Biomed. Mater. Res. Part A 107, 802-814 (2019).

19. Jalali Monfared, M. et al. Transplantation of miR-219 overexpressed human endometrial stem cells encapsulated in fibrin hydrogel in spinal cord injury. J. Cell. Physiol. 234, 18887-18896 (2019).

20. Hasanzadeh, E. et al. Defining the role of $17 \beta$-estradiol in human endometrial stem cells differentiation into neuron-like cells. Cell Biol. Int. 45, 140-153 (2021).

21. Shirian, S. et al. Comparison of capability of human bone marrow mesenchymal stem cells and endometrial stem cells to differentiate into motor neurons on electrospun poly ( $\varepsilon$-caprolactone) scaffold. Mol. Neurobiol. 53, 5278-5287 (2016).

22. Jin, M. C., Medress, Z. A., Azad, T. D., Doulames, V. M. \& Veeravagu, A. Stem cell therapies for acute spinal cord injury in humans: A review. Neurosurg. Focus 46, E10. https://doi.org/10.3171/2018.12.focus18602 (2019).

23. Zavvarian, M.-M., Toossi, A., Khazaei, M., Hong, J. \& Fehlings, M. Novel innovations in cell and gene therapies for spinal cord injury. F1000Research 9, 1-11 (2020). 
24. Rauck, B. M., Novosat, T. L., Oudega, M. \& Wang, Y. Biocompatibility of a coacervate-based controlled release system for protein delivery to the injured spinal cord. Acta Biomater. 11, 204-211 (2015).

25. Tosolini, A. P. \& Sleigh, J. N. Motor neuron gene therapy: Lessons from spinal muscular atrophy for amyotrophic lateral sclerosis. Front. Mol. Neurosci. 10, 405 (2017).

26. Mahmoodi, N. et al. Microtubule stabilizer epothilone B as a motor neuron differentiation agent for human endometrial stem cells. Cell Biol. Int. 44, 1168-1183 (2020).

27. Demers, C. J., Cox, G., Collins, S. D. \& Smith, R. L. in 201638 th Annual International Conference of the IEEE Engineering in Medicine and Biology Society (EMBC) 477-480 (IEEE).

28. Schenke, M., Schjeide, B.-M., Püschel, G. P. \& Seeger, B. Analysis of motor neurons differentiated from human induced pluripotent stem cells for the use in cell-based botulinum neurotoxin activity assays. Toxins (Basel) 12, 276 (2020).

29. Kapitein, L. C. \& Hoogenraad, C. C. Building the neuronal microtubule cytoskeleton. Neuron 87, 492-506 (2015).

30. Dent, E. W. \& Baas, P. W. Microtubules in neurons as information carriers. J. Neurochem. 129, 235-239 (2014).

31. Jang, E. H. \& Sim, A. Effects of microtubule stabilization by epothilone B depend on the type and age of neurons. Neural Plast. 2016, $5056418(2016)$.

32. Erturk, A., Hellal, F., Enes, J. \& Bradke, F. Disorganized microtubules underlie the formation of retraction bulbs and the failure of axonal regeneration. J. Neurosci. 27, 9169-9180. https://doi.org/10.1523/jneurosci.0612-07.2007 (2007).

33. Bonini, S. A., Mastinu, A., Ferrari-Toninelli, G. \& Memo, M. Potential role of microtubule stabilizing agents in neurodevelopmental disorders. Int. J. Mol. Sci. 18, 1627 (2017).

34. Baas, P. W., Rao, A. N., Matamoros, A. J. \& Leo, L. Stability properties of neuronal microtubules. Cytoskeleton 73, 442-460 (2016).

35. Varidaki, A., Hong, Y. \& Coffey, E. T. Repositioning microtubule stabilizing drugs for brain disorders. Front. Cell. Neurosci. 12, 226 (2018).

36. Forli, S. Epothilones: From discovery to clinical trials. Curr. Top. Med. Chem. 14, 2312-2321 (2014).

37. Ruschel, J. et al. Axonal regeneration. Systemic administration of epothilone B promotes axon regeneration after spinal cord injury. Science (New York, N.Y.) 348, 347-352. https://doi.org/10.1126/science.aaa2958 (2015).

38. Zhao, W. et al. Mechanisms responsible for the inhibitory effects of epothilone B on scar formation after spinal cord injury. Neural Regen. Res. 12, 478 (2017).

39. Gomez, J. C. et al. Incorporation of retinoic acid releasing microspheres into pluripotent stem cell aggregates for inducing neuronal differentiation. Cell. Mol. Bioeng. 8, 307-319 (2015).

40. Assunção-Silva, R. C., Gomes, E. D., Sousa, N., Silva, N. A. \& Salgado, A. J. Hydrogels and cell based therapies in spinal cord injury regeneration. Stem Cells Int. https://doi.org/10.1155/2015/948040 (2015).

41. Ghorbani, M. et al. Injectable natural polymer compound for tissue engineering of intervertebral disc: In vitro study. Mater. Sci. Eng. C 80, 502-508 (2017).

42. Reis, R. L. et al. Natural-Based Polymers for Biomedical Applications (Elsevier, 2008).

43. Gorgieva, S. \& Kokol, V. Collagen-vs. gelatine-based biomaterials and their biocompatibility: Review and perspectives. Biomater. Appl. Nanomed. 2, 17-52 (2011).

44. Entekhabi, E. et al. Fabrication and in vitro evaluation of 3D composite scaffold based on collagen/hyaluronic acid sponge and electrospun PCL nanofibers for peripheral nerve regeneration. J. Biomed. Mater. Res. Part A 109, 300-312 (2020).

45. Lee, C. H., Singla, A. \& Lee, Y. Biomedical applications of collagen. Int. J. Pharm. 221, 1-22 (2001).

46. Schneider-Barthold, C., Baganz, S., Wilhelmi, M., Scheper, T. \& Pepelanova, I. Hydrogels based on collagen and fibrin-frontiers and applications. BioNanoMaterials 17, 3-12 (2016).

47. Rights are reserved by Raju, A. \& Asole, J. An Overview on Polyethylene Glycol Gelation for Anti-Cancer Activity.

48. Shu, X. Z., Liu, Y., Palumbo, F. S., Luo, Y. \& Prestwich, G. D. In situ crosslinkable hyaluronan hydrogels for tissue engineering. Biomaterials 25, 1339-1348 (2004).

49. Fathi, A. et al. Fabrication of chitosan-polyvinyl alcohol and silk electrospun fiber seeded with differentiated keratinocyte for skin tissue regeneration in animal wound model. J. Biol. Eng. 14, 1-14 (2020).

50. Joshi, S. S., Kuszynski, C. \& Bagchi, D. The cellular and molecular basis of health benefits of grape seed proanthocyanidin extract. Curr. Pharm. Biotechnol. 2, 187-200 (2001).

51. Fine, A. M. Oligomeric proanthocyanidin complexes: History, structure, and phytopharmaceutical applications. Altern. Med. Rev. 5, 144 (2000).

52. Han, B., Jaurequi, J., Tang, B. W. \& Nimni, M. E. Proanthocyanidin: A natural crosslinking reagent for stabilizing collagen matrices. J. Biomed. Mater. Res. Part A 65, 118-124 (2003).

53. Hennink, W. E. \& van Nostrum, C. F. Novel crosslinking methods to design hydrogels. Adv. Drug Deliv. Rev. 64, 223-236 (2012).

54. Ma, B., Wang, X., Wu, C. \& Chang, J. Crosslinking strategies for preparation of extracellular matrix-derived cardiovascular scaffolds. Regen. Biomater. 1, 81-89 (2014).

55. Hasanzadeh, E. et al. Proanthocyanidin as a crosslinking agent for fibrin, collagen hydrogels and their composites with decellularized Wharton's-jelly-extract for tissue engineering applications. J. Bioact. Compat. Polym. 35(6), 554-571 (2020).

56. Ai, J. et al. Derivation of adipocytes from human endometrial stem cells (EnSCs). J. Reprod. Infertil. 13, 151-157 (2012).

57. Zarei-Behjani, Z. et al. Tracking of GFP-labeled unrestricted somatic stem cells transplanted in the sepsis mouse model. Tissue Cell 60, 33-37 (2019).

58. Mahmoodi, N. et al. Are reported methods for synthesizing nanoparticles and microparticles by magnetic stirrer reproducible?. J. Comput. Appl. Mech. 51, 498-500 (2020).

59. Rajan, N., Habermehl, J., Coté, M.-F., Doillon, C. J. \& Mantovani, D. Preparation of ready-to-use, storable and reconstituted type I collagen from rat tail tendon for tissue engineering applications. Nat. Protoc. 1, 2753 (2006).

60. Ebrahimi-Barough, S. et al. Inhibitor of PI3K/Akt signaling pathway small molecule promotes motor neuron differentiation of human endometrial stem cells cultured on electrospun biocomposite polycaprolactone/collagen scaffolds. Mol. Neurobiol. 54, 2547-2554 (2017).

61. George, S., Hamblin, M. R. \& Abrahamse, H. Differentiation of mesenchymal stem cells to neuroglia: In the context of cell signalling. Stem Cell Rev. Rep. 15, 814-826 (2019).

62. Rodríguez-Martínez, J. A., Peterson-Kaufman, K. J. \& Ansari, A. Z. Small-molecule regulators that mimic transcription factors. Biochim. Biophys. Acta 1799, 768-774 (2010).

63. Jahromi, H. K. et al. Enhanced sciatic nerve regeneration by poly-L-lactic acid/multi-wall carbon nanotube neural guidance conduit containing Schwann cells and curcumin encapsulated chitosan nanoparticles in rat. Mater. Sci. Eng. C 109, 110564 (2020).

64. Trawczynski, M., Liu, G., David, B. \& Fessler, R. G. Restoring motor neurons in spinal cord injury with induced pluripotent stem cells. Front. Cell. Neurosci. 13, 369 (2019).

65. Maury, Y. et al. Combinatorial analysis of developmental cues efficiently converts human pluripotent stem cells into multiple neuronal subtypes. Nat. Biotechnol. 33, 89-96 (2015).

66. Madl, C. M., Katz, L. M. \& Heilshorn, S. C. Tuning bulk hydrogel degradation by simultaneous control of proteolytic cleavage kinetics and hydrogel network architecture. ACS Macro Lett. 7, 1302-1307 (2018).

67. Madl, C. M. et al. Maintenance of neural progenitor cell stemness in 3D hydrogels requires matrix remodelling. Nat. Mater. 16, 1233-1242 (2017). 
68. Madl, C. M., LeSavage, B. L., Dewi, R. E., Lampe, K. J. \& Heilshorn, S. C. Matrix remodeling enhances the differentiation capacity of neural progenitor cells in 3D hydrogels. Adv. Sci. 6, 1801716 (2019).

69. Scott, J. E. Extracellular matrix, supramolecular organisation and shape. J. Anat. 187, 259 (1995).

70. Roberts, J. \& Martens, P. Biosynthetic Polymers for Medical Applications 205-239 (Elsevier, 2016).

71. Narimanpour, Z. et al. Silk nanofibrous electrospun scaffold amplifies proliferation and stemness profile of mouse spermatogonial stem cells. Regen. Eng. Transl. Med. https://doi.org/10.1007/s40883-020-00189-5 (2020).

72. Somaiah, C. et al. Collagen promotes higher adhesion, survival and proliferation of mesenchymal stem cells. PLoS One 10, e0145068 (2015).

73. Salasznyk, R. M., Williams, W. A., Boskey, A., Batorsky, A. \& Plopper, G. E. Adhesion to vitronectin and collagen I promotes osteogenic differentiation of human mesenchymal stem cells. J. Biomed. Biotechnol. 2004, 24-34 (2004).

74. Kojima, C. et al. Modulation of cell adhesion and differentiation on collagen gels by the addition of the ovalbumin secretory signal peptide. ACS Biomater. Sci. Eng. 5, 5698-5704 (2019).

75. Wallace, D. G. \& Rosenblatt, J. Collagen gel systems for sustained delivery and tissue engineering. Adv. Drug Deliv. Rev. 55, 1631-1649 (2003).

76. Choi, J. et al. Engineered collagen hydrogels for the sustained release of biomolecules and imaging agents: Promoting the growth of human gingival cells. Int. J. Nanomed. 9, 5189 (2014).

77. Talovic, M., Marcinczyk, M., Ziemkiewicz, N. \& Garg, K. Laminin enriched scaffolds for tissue engineering applications. Adv. Tissue Eng. Regen. Med. 2, 00033 (2017).

78. Foudah, D. et al. Expression of neural markers by undifferentiated mesenchymal-like stem cells from different sources. J. Immunol. Res. 2014, 987678 (2014).

79. Navaei-Nigjeh, M. et al. Enhancing neuronal growth from human endometrial stem cells derived neuron-like cells in threedimensional fibrin gel for nerve tissue engineering. J. Biomed. Mater. Res. Part A 102, 2533-2543 (2014).

80. Faghihi, F. et al. Differentiation potential of human bone marrow mesenchymal stem cells into motorneuron-like cells on electrospun gelatin membrane. J. Mol. Neurosci. 55, 845-853 (2015).

81. Hester, M. E. et al. Rapid and efficient generation of functional motor neurons from human pluripotent stem cells using gene delivered transcription factor codes. Mol. Ther. 19, 1905-1912 (2011).

82. Qu, Q. et al. High-efficiency motor neuron differentiation from human pluripotent stem cells and the function of Islet-1. Nat. Commun. 5, 3449. https://doi.org/10.1038/ncomms4449 (2014).

83. Faghihi, F. et al. Differentiation potential of human chorion-derived mesenchymal stem cells into motor neuron-like cells in twoand three-dimensional culture systems. Mol. Neurobiol. 53, 1862-1872 (2016).

84. Park, S. et al. Differentiation of motor neuron-like cells from tonsil-derived mesenchymal stem cells and their possible application to neuromuscular junction formation. Int. J. Mol. Sci. 20, 2702 (2019).

85. Sances, S. et al. Modeling ALS with motor neurons derived from human induced pluripotent stem cells. Nat. Neurosci. 19, 542 (2016).

86. Bianchi, F. et al. Rapid and efficient differentiation of functional motor neurons from human iPSC for neural injury modelling. Stem Cell Res. 32, 126-134 (2018).

87. Faravelli, I. et al. Motor neuron derivation from human embryonic and induced pluripotent stem cells: Experimental approaches and clinical perspectives. Stem Cell Res. Ther. 5, 87 (2014).

88. Liu, J. et al. Acellularized spinal cord scaffolds incorporating bpV (pic)/PLGA microspheres promote axonal regeneration and functional recovery after spinal cord injury. RSC Adv. 10, 18677-18686 (2020).

89. Sengottuvel, V., Leibinger, M., Pfreimer, M., Andreadaki, A. \& Fischer, D. Taxol facilitates axon regeneration in the mature CNS. J. Neurosci. 31, 2688-2699 (2011).

90. Cao, Y.-N. et al. Recent advances in microtubule-stabilizing agents. Eur. J. Med. Chem. 143, 806-828 (2018).

91. Chao, C. C., Kan, D., Lo, T. H., Lu, K. S. \& Chien, C. L. Induction of neural differentiation in rat C6 glioma cells with taxol. Brain Behav. 5, e00414 (2015).

92. Park, J. S. et al. Electrical pulsed stimulation of surfaces homogeneously coated with gold nanoparticles to induce neurite outgrowth of PC12 cells. Langmuir 25, 451-457 (2009).

93. McCaig, C. D., Rajnicek, A. M., Song, B. \& Zhao, M. Controlling cell behavior electrically: Current views and future potential. Physiol. Rev. 85, 943-978 (2005).

94. Shi, G., Rouabhia, M., Meng, S. \& Zhang, Z. Electrical stimulation enhances viability of human cutaneous fibroblasts on conductive biodegradable substrates. J. Biomed. Mater. Res. Part A 84, 1026-1037 (2008).

95. Adel, M. et al. Investigating the effects of electrical stimulation via gold nanoparticles on in vitro neurite outgrowth: Perspective to nerve regeneration. Microelectron. Eng. 173, 1-5 (2017).

96. Zhang, Q. et al. Electrical stimulation with a conductive polymer promotes neurite outgrowth and synaptogenesis in primary cortical neurons in 3D. Sci. Rep. 8, 1-10 (2018).

\section{Acknowledgements}

The authors would like to thank Dr. Zeinab Zarei-Behjani for her kind help and technical assistance for hEnSCs GFP labeling.

\section{Author contributions}

This work is part of a Ph.D. thesis of the first author (NM) under the supervision and support of VRM and JA to achieve the Ph.D. of Tissue Engineering from Tehran University of Medical Sciences (The thesis/contract number 9311598022 in the date 2016-11-5). NM did all the techniques, analysis, interpretation of the data and manuscript drafting. Z.H. and S.E. were the advisors for this work. They greatly facilitate laboratory work and troubleshooting. E.H. helped to isolate and culture stem cells from biopsy. Moreover, V.R.M., Z.H., S.E., E.H. and H.N. edited the manuscript from different aspects. A.V. as an expert and native English speaker edited the manuscript. All authors read and approved the final manuscript.

\section{Funding}

This work was supported by Sina Trauma and Surgery Research Center, Tehran University of Medical Sciences (Grant number: 30424-38-03-94) and is part of a Ph.D. thesis of the first author (NM) under the supervision of VRM and JA to achieve the Ph.D. of Tissue Engineering from Tehran University of Medical Sciences (The thesis/ contract number 9311598022 in the date 2016-11-5). 


\section{Competing interests}

Alexander R. Vaccaro is a board member of AOSpine, Innovative Surgical Design, Association of Collaborative Spine Research, DePuy; Consultant at Medtronics, Stryker Spine, Globus, Stout Medical, Gerson Lehrman Group, Guidepoint Global, Medacorp, Innovative Surgical Design, Orthobullets, Ellipse, Vertex, Medtronics; Royalty at Stryker Spine, Biomet Spine, Globus, Aesculap, Thieme, Jaypee, Elsevier, Taylor Francis. All remaining authors declare that they have no financial or non-financial/personal conflict exists and also no commercial associations that might pose a conflict of interest in connection with the submitted article.

\section{Additional information}

Correspondence and requests for materials should be addressed to V.R.-M.

Reprints and permissions information is available at www.nature.com/reprints.

Publisher's note Springer Nature remains neutral with regard to jurisdictional claims in published maps and institutional affiliations.

(c) (i) Open Access This article is licensed under a Creative Commons Attribution 4.0 International License, which permits use, sharing, adaptation, distribution and reproduction in any medium or format, as long as you give appropriate credit to the original author(s) and the source, provide a link to the Creative Commons licence, and indicate if changes were made. The images or other third party material in this article are included in the article's Creative Commons licence, unless indicated otherwise in a credit line to the material. If material is not included in the article's Creative Commons licence and your intended use is not permitted by statutory regulation or exceeds the permitted use, you will need to obtain permission directly from the copyright holder. To view a copy of this licence, visit http://creativecommons.org/licenses/by/4.0/.

(C) The Author(s) 2021 